\title{
Investigations of boundary layer structure, cloud characteristics and vertical mixing of aerosols at Barbados with large eddy simulations
}

\author{
M. Jähn ${ }^{1}$, D. Muñoz-Esparza ${ }^{2}$, F. Chouza ${ }^{3}$, O. Reitebuch ${ }^{3}$, O. Knoth ${ }^{1}$, M. Haarig ${ }^{1}$, and A. Ansmann ${ }^{1}$ \\ ${ }^{1}$ Leibniz Institute for Tropospheric Research, Permoserstraße 15, 04318 Leipzig, Germany \\ ${ }^{2}$ Earth and Environmental Sciences Division (EES-16), Los Alamos National Laboratory, P.O. Box 1663, \\ Los Alamos, New Mexico 87545, USA \\ ${ }^{3}$ Deutsches Zentrum für Luft- und Raumfahrt (DLR), Institute of Atmospheric Physics, Münchner Straße 20, \\ 82234 Oberpfaffenhofen-Wessling, Germany
}

Correspondence to: M. Jähn (jaehn@tropos.de)

Received: 31 July 2015 - Published in Atmos. Chem. Phys. Discuss.: 24 August 2015

Revised: 10 December 2015 - Accepted: 14 December 2015 - Published: 21 January 2016

\begin{abstract}
Large eddy simulations (LESs) are performed for the area of the Caribbean island Barbados to investigate island effects on boundary layer modification, cloud generation and vertical mixing of aerosols. Due to the presence of a topographically structured island surface in the domain center, the model setup has to be designed with open lateral boundaries. In order to generate inflow turbulence consistent with the upstream marine boundary layer forcing, we use the cell perturbation method based on finite amplitude potential temperature perturbations. In this work, this method is for the first time tested and validated for moist boundary layer simulations with open lateral boundary conditions. Observational data obtained from the SALTRACE field campaign is used for both model initialization and a comparison with Doppler wind and Raman lidar data. Several numerical sensitivity tests are carried out to demonstrate the problems related to "gray zone modeling" when using coarser spatial grid spacings beyond the inertial subrange of three-dimensional turbulence or when the turbulent marine boundary layer flow is replaced by laminar winds. Especially cloud properties in the downwind area west of Barbados are markedly affected in these kinds of simulations. Results of an additional simulation with a strong trade-wind inversion reveal its effect on cloud layer depth and location. Saharan dust layers that reach Barbados via long-range transport over the North Atlantic are included as passive tracers in the model. Effects of layer thinning, subsidence and turbulent downward transport near the layer bottom at $z \approx 1800 \mathrm{~m}$ become apparent. The exact position of these layers and strength of downward
\end{abstract}

mixing is found to be mainly controlled atmospheric stability (especially inversion strength) and wind shear. Comparisons of LES model output with wind lidar data show similarities in the downwind vertical wind structure. Additionally, the model results accurately reproduce the development of the daytime convective boundary layer measured by the Raman lidar.

\section{Introduction}

A series of ground-based and airborne remote sensing measurements took place at and around Barbados during the SALTRACE (Saharan Aerosol Long-range Transport and Aerosol-Cloud-Interaction Experiment) 2013 summer campaign. Since Barbados is the easternmost island in the Caribbean and steady easterly trade winds are present, it is not affected by other surrounding islands. For that reason, Barbados is suitable for island effect studies both from the measurement and the modeling point of view. First of all, mineral dust emitted from the Saharan region is transported for more than $4000 \mathrm{~km}$ over the Atlantic Ocean with almost no anthropogenic influence. Dust layers arriving at Barbados can be detected with respect to layer height and thickness as well as aerosol composition. Secondly, cloud studies are possible due to persistent trade-wind circulation at the eastern Caribbean. For example, extensive investigations on shallow cumulus cloud properties and their response to different ambient cloud condensation nuclei (CCN) num- 
ber concentrations took place during the CARRIBA (Cloud, Aerosol, Radiation and tuRbulence in the trade wInd regime over BArbados) project in 2010/2011 (Siebert et al., 2013). Within CARRIBA, airborne in situ measurements were conducted east of Barbados. The field site of the Max Planck Institute for Meteorology (MPI-M), Hamburg, Germany, with ground-based instruments is located at the east coast as well. The choice of these locations ensures that the island itself has very little to no influence on the measurements and thus marine boundary layer properties can be accurately investigated. During SALTRACE, the TROPOS (Leibniz Institute for Tropospheric Research, Leipzig) and LMU (LudwigMaximilians-Universität Munich) field sites were located at the area of the local Caribbean Institute for Meteorology and Hydrology (CIMH) near the west coast of Barbados (see Fig. 1), whereas the DLR (Deutsches Zentrum für Luftund Raumfahrt) research aircraft Falcon was stationed at the international airport of Barbados. Regarding the measurement field site, incoming air masses at these sites are already influenced by the island due to surface roughness change, different energy fluxes and topographical features. Whereas the first two properties primarily influence the atmospheric boundary layer (ABL), gravity waves caused by the latter also propagate within the free troposphere.

There are several works regarding the understanding of airflow and thermodynamic quantities around Barbados. A first detailed observational study using pilot balloon measurements was done by DeSouza (1972) and further interpreted by Garstang et al. (1975). DeSouza's calculated vertical wind velocity fields showed a daytime divergence and nighttime convergence over the island. Mahrer and Pielke (1976) did a series of two- and three-dimensional numerical studies and found that DeSouza's calculations only hold for a flat island, because he neglected significant effects of terrain slope in his divergence calculations. Heat island effects on vertical mixing of aerosols at Cape Verde islands were studied by Engelmann et al. (2011) using aircraft lidar measurements and idealized large eddy simulations (LESs) with flat island surfaces. They found indications that the differential heating and the orographic impact control downward mixing of African aerosols, which results in a complex vertical layering over the Cape Verde region. Taking the topographical structures into account, Mahrer and Pielke (1976) pointed out some main characteristics, e.g., diurnal changes in the vertical wind velocity fields downwind (i.e., west coast of Barbados) with sinking motions over the center and western part of the island and an upwind cell off the west coast. Considering numerical sensitivity studies by Savijärvi and Matthews (2004, SM04 hereafter), the general conclusion was that these forced rising and sinking motions and their consecutive effects can only be explained if island orography is included in the numerical models. In their 2-D study, SM04 added a $200 \mathrm{~m}$ high central mountain to a $20 \mathrm{~km}$ wide island and showed that sea-breeze circulations are enhanced by upslope winds during the day. These topographically forced components will dominate if the large-scale mean wind is in the order of magnitude of at least $10 \mathrm{~m} \mathrm{~s}^{-1}$, which is the case for Barbados. Smith et al. (1997) assigned different island structures to different mountain wake types. Since the highest elevation of Barbados (Mt. Hillaby, with a height of 340 ma.s.l.) does not exceed the critical height for wave breaking, no wind wake can develop. However, a long trail of cumulus clouds extending westwards can evolve during the afternoon hours (cumulus cloud street). Kirshbaum and Fairman (2015) found that surface fluxes control the downwind circulation strength and the trade inversion controls precipitation and thus the disruption of cloud trails. Other influence factors like terrain height, wind speed and their interactions have multiple impacts on flow regimes, turbulence, cloud trail lengths etc. Another study on island effects with similar topographical heights compared to Barbados was done by Minda et al. (2010). They investigated the evolution of the convective boundary layer (CBL) above Okinawa Island, Japan. It was found that for a flat island simulation, the warmed land already induces a distinct roll cloud that is in agreement with the observations. However, the inclusion of island terrain leads to reinforced moisture uplifts, which in turn induce strong convection that can penetrate into the free atmosphere. Idealized numerical studies were conducted by Kirshbaum and Grant (2012) to investigate the impact of mesoscale ascent (with an island height of $500 \mathrm{~m}$ ) on cumulus convection. There, a particularly important process with regard to the mean horizontal cloud size has been found. The broader the clouds are, the lower is the fractional entrainment rate in these clouds, which in the end leads to an increase in precipitation rates downstream. A key result from another combined theoretical and numerical study by Kirshbaum and Wang (2014) was that nonlinear interactions between mechanical and thermal flow over taller mountains were significant and thus lead to a strengthening of the leeside convergence band.

There are also many studies where the focus lies on the orographic influence of tall islands (e.g., Hawaii Island or Dominica with mountain heights above $1 \mathrm{~km}$ ) on the leeward flow and precipitation patterns. Esteban and Chen (2008) state that for a strong trade-wind flow, the daily rainfall totals at the windward side of the island of Hawaii show a nocturnal maximum due to the convergence of katabatic flow, whereas for weak trades $\left(\leq 5 \mathrm{~m} \mathrm{~s}^{-1}\right)$ the rainfall amounts have their maximum in the late afternoon due to anabatic winds. In a work by Smith et al. (2009), orographic precipitation for the Caribbean island Dominica was studied. There, the conditionally unstable trade-wind layer together with terrainforced lifting leads to convective triggering over the windward slope. The reduced instability on the lee side destroys convective clouds and creates a rainless area. A complementary study with airborne observations and cloud-resolving modeling for the same island was performed by Minder et al. (2013). The comparison showed that the dynamical structures are very well reproduced but that it was difficult to 

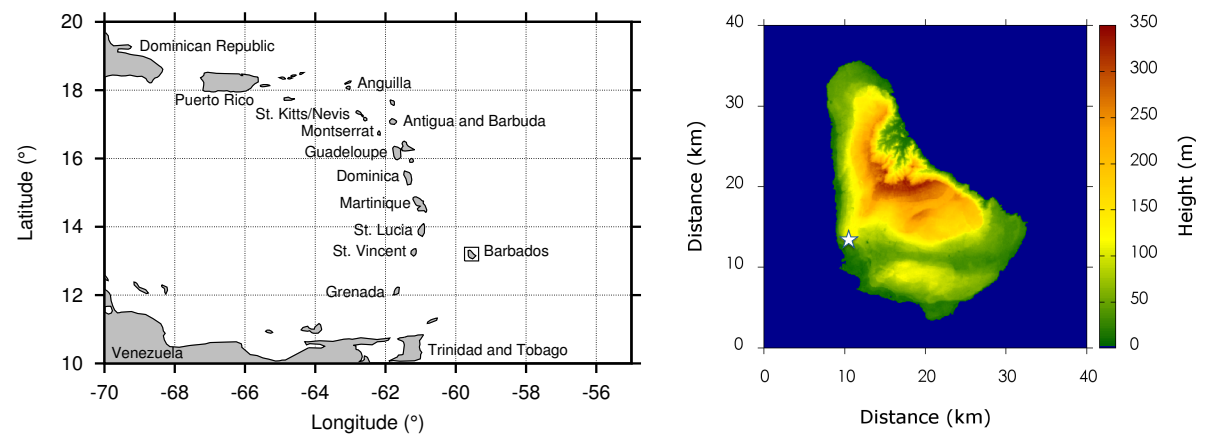

Figure 1. Left panel: part of the Caribbean including the Lesser Antilles. Right panel: topographical map of Barbados. The topographical data are obtained from the Consortium for Spatial Information (CGIAR-CSI) Shuttle Radar Topography Mission (SRTM) data set at $200 \mathrm{~m}$ resolution. The white star denotes the location of the CIMH, which is close to the measurement field site.

reproduce the observed rainfall using the model. Overall, mesoscale flow controls convection and rainfall over Dominica. At lower wind speeds, the circulations seem to be more thermally driven by solar heating.

The main objective of this work is to study local island effects on the modification of the boundary layer structure, microphysical properties and downwind vertical mixing of aerosols for selected days during the first SALTRACE field campaign. Regarding aerosols, especially Saharan dust, it is known from several studies that notable amounts of mineral dust reach Barbados via long-range transport over the North Atlantic, e.g., from first observations at the end of the 1960s (Prospero et al., 1970; Prospero and Carlson, 1970) or from back-trajectory calculations by Ellis and Merrill (1995).

Within this work, the following questions are addressed:

- How does the model setup have to be chosen to get an as realistic as possible representation of an island-ocean system in the trade-wind regime through the example of Barbados?

- How do turbulent inflow characteristics and grid spacing affect the simulation results?

- Can the daytime convective island boundary layer explain downward mixing of low-altitude Saharan dust layers?

- Are the simulation results comparable with lidar measurements over and in the lee of the island?

This paper is structured as follows. Section 2 deals with the general model setup. There, the numerical method, model physics, computational domain, boundary conditions, initial data and forcings are described. To generate a turbulent marine boundary layer, a novel method based on potential temperature perturbations is adopted, verified and applied to our numerical model and particular setup. Results for two case studies in June 2013 and two sensitivity tests are presented and discussed in Sect. 3. In Sect. 4, the simulation results are compared with stationary and airborne lidar data. Section 5 provides a summary and concluding remarks.

\section{Model setup}

All LESs are performed with the latest version of the non-hydrostatic, fully compressible All Scale Atmospheric Model (ASAM). An extensive model description is presented in Jähn et al. (2015), both covering numerical discretization methods and physical parameterizations. A special feature of ASAM is the usage of so-called cut cells for the orography. There, a grid box is cut by the intersection of the orographical structure. This method can handle steep terrain gradients and prevents discretization errors compared to traditional methods like terrain-following coordinates, also conserving the original shape of the topography to a high degree. The dynamical core solves the flux-form tendency equations for mass, momentum, energy (in terms of density potential temperature) and other scalars. The most important physical parameterizations include a Smagorinsky subgrid-scale model and a two-moment cloud microphysics scheme. Further details on the model are described in Appendix A.

In the next subsections, the computational domain, boundary conditions (BC), data initialization and forcings for the cases of study are described, followed by a novel method to generate inflow turbulence.

\subsection{Domain and boundary conditions}

To simulate atmospheric flow for the island-ocean system, the size of the model domain has to have appropriate values dependent on the island size. The main criterion in this case is that a marine boundary layer has to develop at least several kilometers before it interferes with the island area. Also, the downwind area should approximately be twice of the island width so that resulting structures induced by the island can be properly represented. Since Barbados is a $24 \mathrm{~km}$ wide (west-east) and $34 \mathrm{~km}$ long (south-north) island, a model domain with a spatial extent of $102.4 \mathrm{~km} \times 102.4 \mathrm{~km}$ is chosen. The island is located at the domain center. The model top is set to $5 \mathrm{~km}$ altitude. Because of the required domain size and for computational reasons, the horizontal grid spacing is set 
to $\Delta x=\Delta y=200 \mathrm{~m}$. Such a resolution can be considered a "coarse" LES; however, it is sufficient to resolve some portion of inertial range scales, as will be shown later on through spectral analysis.

Due to the presence of the island area, non-cyclic lateral boundary conditions have to be used. Within the finite volumes/differences discretization strategy adopted herein, a "zero-gradient" boundary condition is applied to all scalars and velocity components at each lateral boundary (north, east, south, west). This means that the boundaryperpendicular flux for these quantities is set to zero, which leads to a simple radiation condition near the outlets with minimal wave reflection. A pressure correction for sound waves is applied to each actual normal velocity component and not to the initial wind profile, which also suppresses artificial wave reflection near the inflow boundary. This setup ensures stability for the whole simulation time and works appropriately with the turbulence generation method, as shown at the end of this section.

For the top boundary, a free-slip condition is applied, i.e., the gradient of the tangential velocity component is zero. In order to prevent gravity wave reflection, an additional relaxation term is applied on the right-hand side of the momentum equations:

$\Phi^{n+1}=\ldots-\Delta t \cdot \rho K(d)\left(\Phi^{n}(d)-\Phi^{0}\right)$,

with a damping function depending on the distance to the top boundary $d$ :

$K(d)= \begin{cases}d_{f} \sin ^{2}\left(\frac{\pi}{2} \frac{d_{w}-d}{d_{w}}\right) & d<d_{w}, \\ 0 & d \geq d_{w} .\end{cases}$

This damping layer is applied above $d_{w}=4 \mathrm{~km}$ model height (20 vertical layers) with a damping parameter $d_{f}=$ $1 \times 10^{-3}$.

Surface boundary conditions are represented by a momentum flux parameterization based on the Monin-Obukhov similarity theory (Monin and Obukhov, 1954):

$$
\begin{aligned}
\tau_{z x} & =-\rho C_{\mathrm{m}}\left|\boldsymbol{v}_{h}\right| u, \\
\tau_{z y} & =-\rho C_{\mathrm{m}}\left|\boldsymbol{v}_{h}\right| v .
\end{aligned}
$$

$C_{\mathrm{m}}$ is the drag coefficient for momentum, which is defined as follows:

$C_{\mathrm{m}}=\frac{k^{2}}{\Psi_{\mathrm{M}}^{2}}$,

with

$\Psi_{\mathrm{M}}=\ln \left(\frac{z+z_{0}}{z_{0}}\right)-\phi_{\mathrm{m}}\left(\frac{z}{L}\right)$,

and $\phi_{\mathrm{m}}$ representing the integrated similarity function. $L$ stands for the Obukhov length and $k$ is the von Kármán constant.
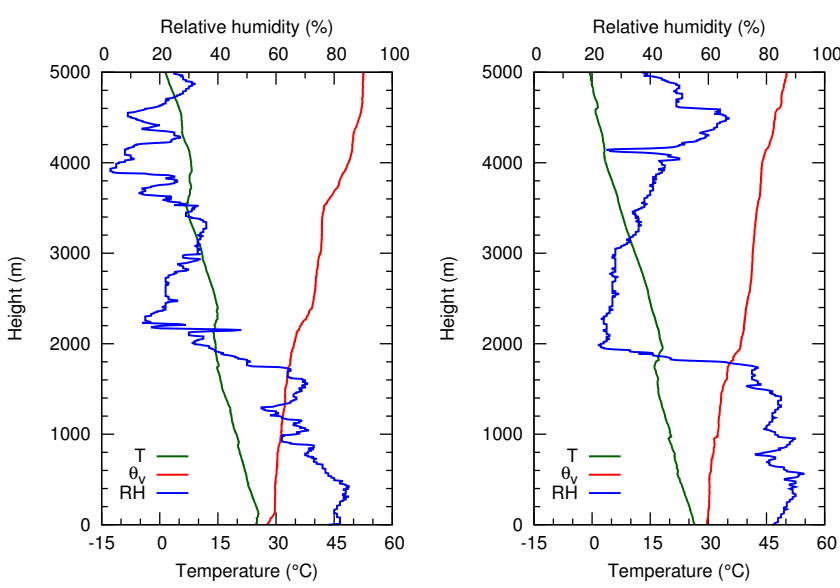

Figure 2. Nighttime radiosonde soundings on 22 June 2013 (left) and 27 June 2013 (right).

The topographic data are obtained from the Consortium for Spatial Information (CGIAR-CSI) Shuttle Radar Topography Mission (SRTM) data set (http://srtm.csi.cgiar.org) at $200 \mathrm{~m}$ resolution. A simple smoothing algorithm is applied to guarantee a proper grid pre-processing. In the smoothed data set, the maximum elevation is lowered by about $15 \mathrm{~m}$ compared to the raw topography data, which is an acceptable level.

Table 1 summarizes the model configuration for the Barbados LESs performed in Sect. 3.

\subsection{Initial data}

The two cases examined (22 and 27 June 2013) mainly differ in their atmospheric state and geostrophic forcing. Measured nighttime radiosonde profiles of temperature and humidity are directly used for model initialization (Fig. 2), which reduces the complexity of the simulations due to the absence of horizontal inhomogeneities and a time-varying background state. There are two reasons behind the choice of using single profiles instead of averaging multiple profiles. Firstly, a single initial profile is better for comparing the LES results with lidar data (cf. Sect. 4), which are obtained for a few selected cases during SALTRACE. Secondly, trade-wind inversions are only poorly represented when the soundings are averaged over many cases. This becomes apparent when considering the sharply defined inversion at the 27 June case, which is shown later on. Air density and pressure profiles are obtained by vertical integration with respect to hydrostatic equilibrium. Some simplifications are assumed for the geostrophic forcing. The wind direction is purely east (i.e., $d=90^{\circ}$ and $v_{g}=0$ ), which is also for simplicity and to make it easier to define upwind and downwind regimes later on. The vertical wind profiles are expressed as piecewise linear functions for both cases. For the 22 June case, the initial wind at first linearly decreases above $z=1600 \mathrm{~m}$ altitude and then increases 
Table 1. LES model configuration for the simulations performed in Sect. 3 .

\begin{tabular}{ll}
\hline Model parameter & Value/description \\
\hline Domain & $102.4 \times 102.4 \times 5 \mathrm{~km}^{3}$ \\
Grid cells & $512 \times 512 \times 100$ \\
Time step & $4 \mathrm{~s}$ \\
Horizontal grid spacing & $200 \mathrm{~m}$ \\
Vertical grid spacing & $50 \mathrm{~m}$ \\
Start time (LT) & $02: 00$ \\
End time (LT) & $22: 00$ \\
Topography data & SRTM, 200 m resolution \\
Turbulence scheme & Standard Smagorinsky SGS model \\
Cloud microphysics & Two-moment scheme (no ice phase) by Seifert and Beheng (2006) \\
Wind direction & East $\left(90^{\circ}\right)$ \\
Lateral BC & Open radiative \\
Surface BC & Monin-Obukhov \\
Top BC & Free slip \\
Damping layer & For $z \geq 4.0 \mathrm{~km}$ \\
\hline
\end{tabular}

again above $z=3000 \mathrm{~m}$ :

$$
\begin{aligned}
& u_{i, 1}(z)= \\
& \begin{cases}-10.0 \mathrm{~m} \mathrm{~s}^{-1} \frac{\log \left(z / z_{0}\right)}{\log \left(700 \mathrm{~m} / z_{0}\right)}, & z \leq 0.7 \mathrm{~km} \\
-10.0 \mathrm{~m} \mathrm{~s}^{-1}, & z \leq 1.6 \mathrm{~km} \\
-10.0 \mathrm{~m} \mathrm{~s}^{-1}+4.29 \times 10^{-3} \mathrm{~s}^{-1} & \\
\quad(z-3000 \mathrm{~m}), & 1.6 \mathrm{~km}<z \leq 3.0 \mathrm{~km} \\
-4.0 \mathrm{~m} \mathrm{~s}^{-1}-2.0 \times 10^{-3} \mathrm{~s}^{-1} & \\
\cdot(z-5000 \mathrm{~m}), & 3.0 \mathrm{~km}<z \leq 5.0 \mathrm{~km},\end{cases}
\end{aligned}
$$

with a roughness length $z_{0}=0.01 \mathrm{~m}$. A change in wind direction to southwest is observed within the layer where the wind speed decreases. However, this is not captured by the LES due to the simplifications and assumptions mentioned above. Therefore, the effect of wind directional shear might be underestimated in the model for this case. The change in wind direction $\left( \pm 15^{\circ}\right)$ is rather small at other altitudes, so the LES input profile can be considered a good approximation. For the 27 June case, the initial wind linearly decreases above $z=3000 \mathrm{~m}$ altitude:

$$
\begin{aligned}
& u_{i, 2}(z)= \\
& \begin{cases}-11.5 \mathrm{~m} \mathrm{~s}^{-1} \frac{\log \left(z / z_{0}\right)}{\log \left(700 \mathrm{~m} / z_{0}\right)}, & z \leq 0.7 \mathrm{~km} \\
-11.5 \mathrm{~m} \mathrm{~s}^{-1}, & z \leq 3 \mathrm{~km} \\
-11.5 \mathrm{~m} \mathrm{~s}^{-1}+5.25 \times 10^{-3} \mathrm{~s}^{-1} & \\
\cdot(z-3000 \mathrm{~m}), & z>3 \mathrm{~km} .\end{cases}
\end{aligned}
$$

In this profile there is no distinct change in wind direction. Figure 3 visualizes the measured (green lines) and parameterized (red lines) velocity profiles for both cases. The LES background wind profiles are parameterized to closely match the soundings. Within the boundary layer, the LES profile should be near the nighttime measurements (dark-green line) because this is mainly a representation of the marine boundary layer. For the free troposphere, the LES profile should roughly be a mean of all three soundings, since no large-scale
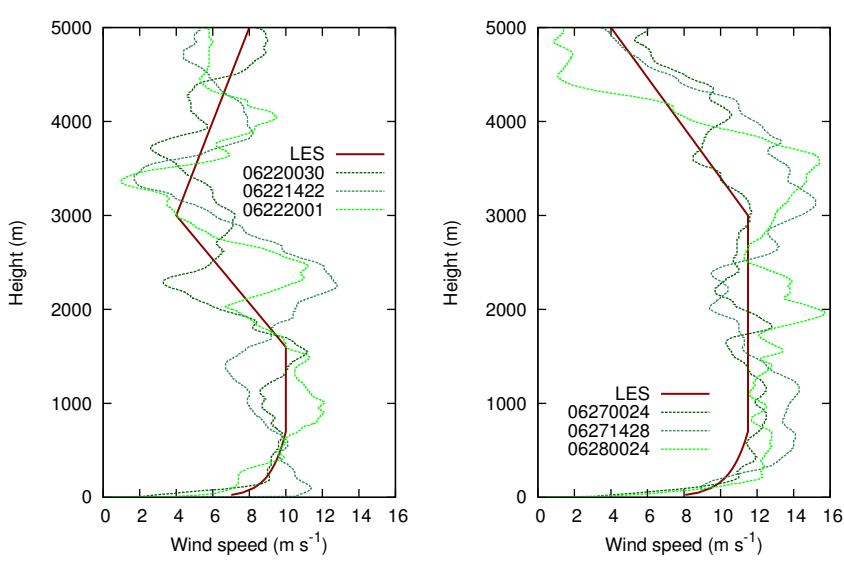

Figure 3. Parameterized (LES) and measured wind profiles from radiosondes on 22 June 2013 (left) and 27 June 2013 (right). Names indicate date and time in UTC.

advection term is applied on the wind components during the simulation time.

Table 2 shows a comparison of the two simulated cases with respect to mean flow properties, trade inversion strength, moisture load (all derived from radiosonde profiles), CCN concentrations (obtained by ground-based measurements at Ragged Point station) and the location of the Saharan dust layer (estimated from BERTHA lidar measurements at CIMH). The differences in the geostrophic forcing are already discussed. Regarding the atmospheric stability, there is a much stronger trade inversion for the 27 June case with a local virtual potential temperature gradient of $14 \mathrm{~K} \mathrm{~km}^{-1}$. As mentioned in the introduction, the trade inversion controls the amount of precipitation and the lifetime of cloud streets. Furthermore, there is a $18 \%$ stronger moisture load for the 27 June case, where a faster cloud development is expected. Due to the vertical and temporal variability in the 


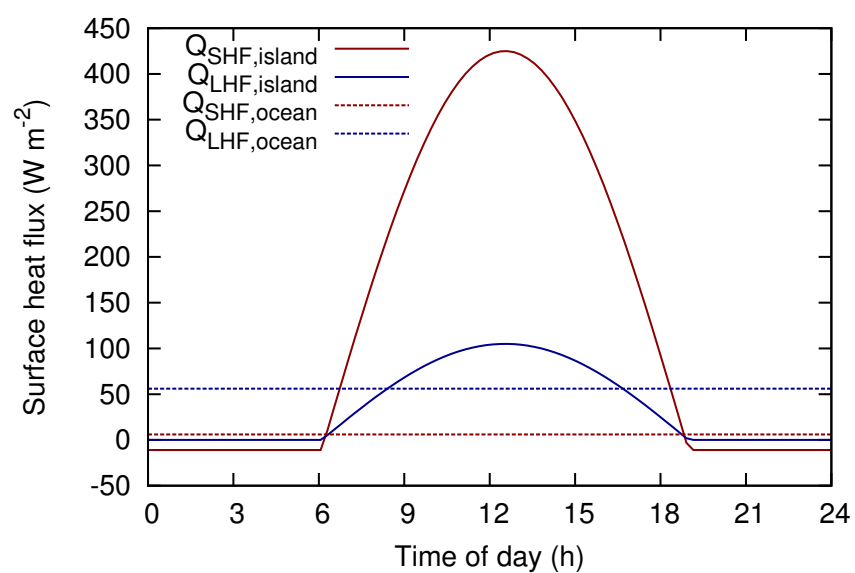

Figure 4. Parameterized diurnal variation in sensible (SHF) and latent heat fluxes (LHF) over island and ocean areas.

$\mathrm{CCN}$ number concentrations, a mean value of $300 \mathrm{~cm}^{-3}$ has been chosen for both cases, which is a typical magnitude for days with a moderate dust load, where aerosol optical depths between 0.2 and 0.4 are observed.

\subsection{Forcings}

Surface sensible and latent heat fluxes over the island and the ocean are obtained by separate 1-D simulations with full model physics. The parameterizations there include the radiation scheme (Fu and Liou, 1993) as well as land-use and soil models. The soil class "loam" was chosen to represent the average island soil type. Hydraulic and thermal parameters of this soil type can be found in Doms et al. (2011) and Jähn et al. (2015). For land surface parameterization, "shrubland" appears to be a good compromise between coastal beach areas and forest in the island interior. The roughness length of this land type is $z_{\mathrm{R} \text {,island }}=0.2 \mathrm{~m}$, whereas the ocean roughness length is set to $z_{\text {R,ocean }}=0.01 \mathrm{~m}$. The usage of direct (compared to interactive) fluxes reduces computational costs for the LES runs and makes it easier to potentially reproduce these simulations by other models, especially due to a large number of existing radiation and land-use models. Figure 4 shows the diurnal variation in sensible and latent heat fluxes over the island area. The maximum sensible heat flux over the island is $Q_{\mathrm{SHF}_{\max }}$, island $=425 \mathrm{~W} \mathrm{~m}^{-2}$ and the corresponding maximum latent heat flux is $Q_{\mathrm{LHF}_{\max } \text {, island }}=$ $105 \mathrm{~W} \mathrm{~m}^{-2}$. Surface heat fluxes over the ocean are constant during the whole simulation time with $Q_{\mathrm{SHF}, \text { ocean }}=6 \mathrm{~W} \mathrm{~m}^{-2}$ and $Q_{\mathrm{LHF}, \text { ocean }}=56 \mathrm{~W} \mathrm{~m}^{-2}$. Sunrise is at 05:36 LT and sunset is at 18:29 LT, whereby the fluxes are shifted by $30 \mathrm{~min}$ to represent the delay due the fact that the soil has to be heated first before energy exchange with the lower atmosphere can take place.

Later on, reference simulations with periodic boundary conditions are performed to obtain information of marine boundary layer characteristics. For these simulations, large- scale forcings from the BOMEX LES study of trade-wind cumulus convection (Siebesma et al., 2003) are applied. They include a piecewise linear subsidence velocity profile with an absolute peak value of $-560 \mathrm{mday}^{-1}$, radiative cooling of $-2 \mathrm{Kday}^{-1}$ and large-scale advection of dry air into the lower boundary layer of $-1 \mathrm{~g} \mathrm{~kg}^{-1} \mathrm{day}^{-1}$ :

$$
w_{\mathrm{sub}}= \begin{cases}-4.33 \times 10^{-6} \mathrm{~s}^{-1} z, & z \leq 1500 \mathrm{~m} \\ -0.0065+1.08 \times 10^{-5} \mathrm{~s}^{-1} & \\ \cdot(z-1500 \mathrm{~m}), & 1500 \mathrm{~m}<z \leq 2100 \mathrm{~m} \\ 0.0, & z>2100 \mathrm{~m}\end{cases}
$$$$
\frac{\mathrm{d} \theta}{\mathrm{d} t}=\left\{\begin{array}{ll}
-2.315 \times 10^{-5} \mathrm{~K} \mathrm{~s}^{-1}, & z \leq 1500 \mathrm{~m} \\
-2.315 \times 10^{-5} \mathrm{Ks}^{-1} & \\
+2.315 \times 10^{-8} \mathrm{~K} \mathrm{~s}^{-1} \mathrm{~m}^{-1} & \\
\cdot(z-1500 \mathrm{~m}), & 1500 \mathrm{~m}<z \leq 2500 \mathrm{~m} \\
0.0, & z>2500 \mathrm{~m}
\end{array},\right.
$$

$$
\frac{\mathrm{d} q v}{\mathrm{~d} t}= \begin{cases}-1.2 \times 10^{-8} \mathrm{~s}^{-1}, & z \leq 300 \mathrm{~m} \\ -1.2 \times 10^{-8} \mathrm{~s}^{-1} & \\ +6 \times 10^{-11} \mathrm{~s}^{-1} \mathrm{~m}^{-1} & \\ \cdot(z-300 \mathrm{~m}), & 300 \mathrm{~m}<z \leq 500 \mathrm{~m} \\ 0.0, & z>500 \mathrm{~m}\end{cases}
$$

\subsection{Turbulence generation - the cell perturbation method}

The LES modeling technique has the advantage of allowing explicit resolution of turbulent production and part of the inertial range scales, and is today the most accurate and computationally feasible modeling approach in the context of high Reynolds number flows. LES results are strongly dependent on boundary conditions, therefore requiring specification of realistic inflow turbulence characteristics that propagate through the domain into the area of interest. In order to ensure that the incoming boundary layer characteristics at Barbados correspond to fully developed turbulence consistent with the imposed marine boundary layer forcing, we use the cell perturbation method recently proposed by MuñozEsparza et al. (2014). The cell perturbation method uses a novel stochastic approach based upon finite amplitude perturbations of the potential temperature field applied within a region near the inflow boundaries of the LES domain. This method has demonstrated superior performance when compared to a state-of-the-art synthetic turbulence generator and is computationally inexpensive (Muñoz-Esparza et al., 2015).

Previous studies where the cell perturbation method was developed and validated dealt with transitions from smooth mesoscale flow to nested LES (Muñoz-Esparza et al., 2014, 2015). In these idealized cases, boundary conditions at the LES domain boundaries were imposed from the mesoscale model instantaneous solution (Dirichlet boundary conditions), in which moisture effects were not considered. Herein, we further extend the application of the cell perturbation 
method to turbulence inflow generation for cloud modeling including terrain effects. As explained in earlier sections, zero-gradient open radiative lateral boundary conditions need to be used in order to minimize wave reflections at the boundaries that do develop in fully compressible codes like the ASAM LES model when the domain includes terrain features. In order to test the best configuration for the cell perturbation method in this particular context, we perform a series of calculations where only the upstream region of the Barbados island is considered (i.e., incoming marine boundary layer). The reduced subset of the domain consists of a $51.2 \mathrm{~km} \times 51.2 \mathrm{~km}$ area in the horizontal, with the same vertical extent and large-scale forcing described in Sect. 2.3 for the 22 June 2013 case study. To represent the marine boundary layer conditions that are going to be imposed through the entire simulation period, constant sensible and latent heat fluxes of $Q_{\mathrm{SHF}, \mathrm{ocean}}=6 \mathrm{~W} \mathrm{~m}^{-2}$ and $Q_{\mathrm{LHF}, \text { ocean }}=56 \mathrm{~W} \mathrm{~m}^{-2}$ are used (see Fig. 4).

We explore the sensitivity of the generated turbulence by the cell perturbation method to the optimum perturbation Eckert number, $E c=U_{\mathrm{g}}^{2} / c_{\mathrm{p}} \widetilde{\theta}_{\mathrm{pm}}=0.2$, where $\widetilde{\theta}_{\mathrm{pm}}$ is the maximum potential temperature perturbation, and the perturbations are random and uniformly distributed in the interval $\left[-\widetilde{\theta}_{\mathrm{pm}},+\widetilde{\theta}_{\mathrm{pm}}\right]$. Three square cells adjacent to the east boundary are used, which were found to provide the fastest transition to a fully developed turbulent state (Muñoz-Esparza et al., 2015). The cell size is set to $4 \times 4$ grid points to ensure that the cell wavelength falls within the inertial range of three-dimensional turbulence. The perturbation timescale, $t_{\mathrm{p}}$, was obtained from $\Gamma=t_{\mathrm{p}} U_{1}(4 \mathrm{~d} x)^{-1}=1$ (Muñoz-Esparza et al., 2015), with $U_{1}$ being the horizontal wind speed in the first vertical layer, resulting in a frequency to seed instantaneous perturbations of $t_{\mathrm{p}}=145 \mathrm{~s}$. Figure 5 shows instantaneous contours of vertical velocity at $z=z_{i} / 2=375 \mathrm{~m}$ for different perturbation Eckert numbers, $E c=0.2,0.33$ and 0.4 , and for the periodic reference run. The cell perturbation method for the three $E c$ numbers considerably accelerates the formation of three-dimensional turbulent structures that agree with the ones obtained in the reference simulation using periodic lateral boundary conditions. As the perturbation Eckert number increases (maximum perturbation amplitude decreases), the strength of the vertical velocities induced by the temperature perturbations is progressively reduced, and the onset of forcing-consistent turbulence seems to qualitatively occur at earlier distances from the inflow boundary.

In order to have a better understanding of the turbulence initiation and development processes, the energy spectrum evolution in the streamwise direction for the three velocity components is presented in Fig. 6 . The cell perturbation method causes a rapid development of the upperwavenumber portion of the energy spectrum for the $u$ and $v$ components. The larger scales (lower wavenumbers) require longer distances to be established due to large buoyant plumes having to emerge from the surface and populate across the entire extent of the boundary layer. This flow development pattern is consistent with the findings from Muñoz-Esparza et al. (2014) for convective conditions. In contrast, the energy spectrum for the vertical velocity reveals a rapid growth of turbulent energy that reaches levels 10 times greater than the periodic quasi-equilibrium solution (dashed black line) and that progressively dissipates as the flow transitions through the domain. We attribute this behavior to the cell size, $4 \mathrm{~d} x$, which for the resolution employed in this study may fall in the vicinity of the limit of the inertial range. Smaller cell sizes were not considered due to the energy dissipation at high wavenumbers present in finite differences/volumes discretizations. There, an interaction with fully resolved scales and triggering of an accelerated transition to a developed turbulence state would not have taken place. In addition, the use of zero-gradient lateral boundary conditions helps to maintain the signature of the perturbations more than in the case of Dirichlet boundary conditions, hence contributing to strengthen the periodically seeded perturbations. By increasing the perturbation Eckert number from 0.2 to 0.4 (first row vs. third row in Fig. 6), the energy overestimation is damped, and results after a fetch of $40 \mathrm{~km}$ for $E c=0.4$ are in close agreement with the periodic simulation used as a reference and have reached quasiequilibrium converged statistics. The $E c=0.2$ case results in an energy deficit at wavenumbers close to the integral length scale, and also at the highest wavenumbers for the $w$ component. When the cell perturbation method is not used (NOCP panels, bottom row in Fig. 6), dramatic energy deficits are found, together with an unrealistic spiky energy distribution in which the expected energy production and cascade processes are not present.

Finally, we examine the vertical distribution of relevant boundary layer quantities at a downstream distance of $40 \mathrm{~km}$ from the east boundary (i.e., $x=11.2 \mathrm{~km}$ ). Vertical profiles (Fig. 7) show the best agreement with the periodic simulation for the $E c=0.4$ and 0.33 cases, in particular for the turbulent kinetic energy levels and boundary layer structure. Momentum flux profiles exhibit slightly larger values in the first $250 \mathrm{~m}$, due to the differences in the horizontal wind speed distribution near the surface. However, the boundary layer structure is similar, with the differences being related to distinct quasi-equilibrium solutions for the periodic and the open boundary condition simulations. Similar conclusions are found for the sensible and latent heat fluxes. The cell perturbation method was originally developed and tested in the context of dry boundary layers (Muñoz-Esparza et al., 2014, 2015). It is worth emphasizing that we have herein demonstrated for the first time, as can be seen from the latent heat flux profile, that the cell perturbation method has the ability to develop turbulent moisture features that are in agreement with the imposed forcing. The $E c=0.2$ case fails to produce a boundary layer structure that is similar to the reference periodic case, with excessive mixing attributed to an enhanced effect of the perturbations for the reasons mentioned above. Also, the NOCP case does not provide 

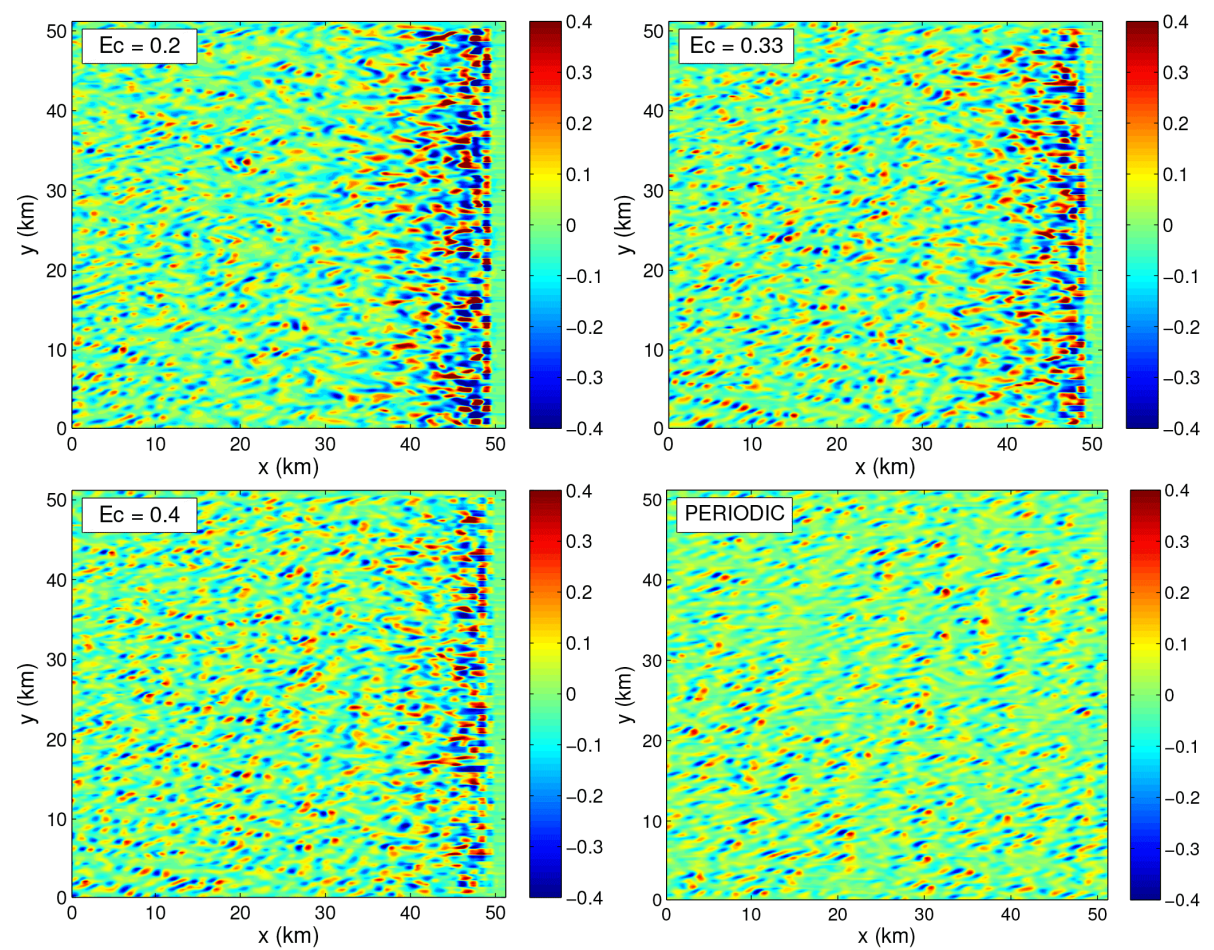

Figure 5. Instantaneous contours of vertical velocity at $z=z_{i} / 2=375 \mathrm{~m}$ for different perturbation Eckert numbers, $E c=0.2,0.33,0.4$, and the periodic case.

realistic turbulent boundary layer features corresponding to a strongly underdeveloped turbulent state. Therefore, we select the $E c=0.4$ setup as the inflow to be used for the island simulations presented in the remainder of the paper since it produces the most rapid development and stabilization of forcing-consistent turbulence. For the island cases, we use a domain with horizontal extent of $102.4 \mathrm{~km} \times 102.4 \mathrm{~km}$, which leaves sufficient fetch for the marine boundary layer to develop prior to the start of interaction with the topography of Barbados and its local stability effects.

\section{Results}

To investigate the effects of the Barbados island area on boundary layer properties, cloud generation and vertical mixing of aerosols, we define two subdomains that are considered to be representative of the upwind and downwind area, respectively. Figure 8 shows the position of these two subdomains. They both cover a base area of $10 \mathrm{~km} \times 20 \mathrm{~km}$ and are used for averaging of vertical profiles and time series of the relevant quantities. The upwind domain east of Barbados (representing the marine boundary layer) is approximately $15 \mathrm{~km}$ away from the eastern boundary to avoid contamination from the inflow boundaries where turbulence has to be generated first. Looking into the model data, it becomes apparent that the flow has to pass at least half of the island area $(\approx 12 \mathrm{~km})$ before a well-mixed convective layer can fully de- velop. For that reason, the downwind subdomain is located between $35 \mathrm{~km}<x<45 \mathrm{~km}$ and thus covers the west coast island area and the marine offshore area in equal parts. The following analysis mainly consists of comparisons between these two regimes to investigate island effects on various parameters.

\subsection{Overview of simulations performed}

Besides the two mentioned case studies, two additional sensitivity studies are part of the island effect analysis. Here, the 22 June 2013 case serves as a reference case (REF). For the first sensitivity case (NOCP), the cell perturbation method is disabled so that the upwind flow is strongly underdeveloped. With this setup, the effect of having a realistic turbulent boundary layer around the island rather than idealized constant winds is investigated. In the next sensitivity case (DX400), the grid resolution is halved from 200 to $400 \mathrm{~m}$ horizontally and from 50 to $100 \mathrm{~m}$ vertically to point out the deficiencies in the use of coarser resolution without appropriate resolved turbulence and gray zone modeling (Wyngaard, 2004) for particular aspects of interest in boundary layers and cloud modeling. In this simulation, the cell perturbation method is also put off since the usage of a turbulent inflow in coarse resolution studies has not been utilized before and, moreover, appears to be questionable because the inertial subrange of the turbulence spectrum is not resolved anymore. The simulation ensemble is completed by the 27 

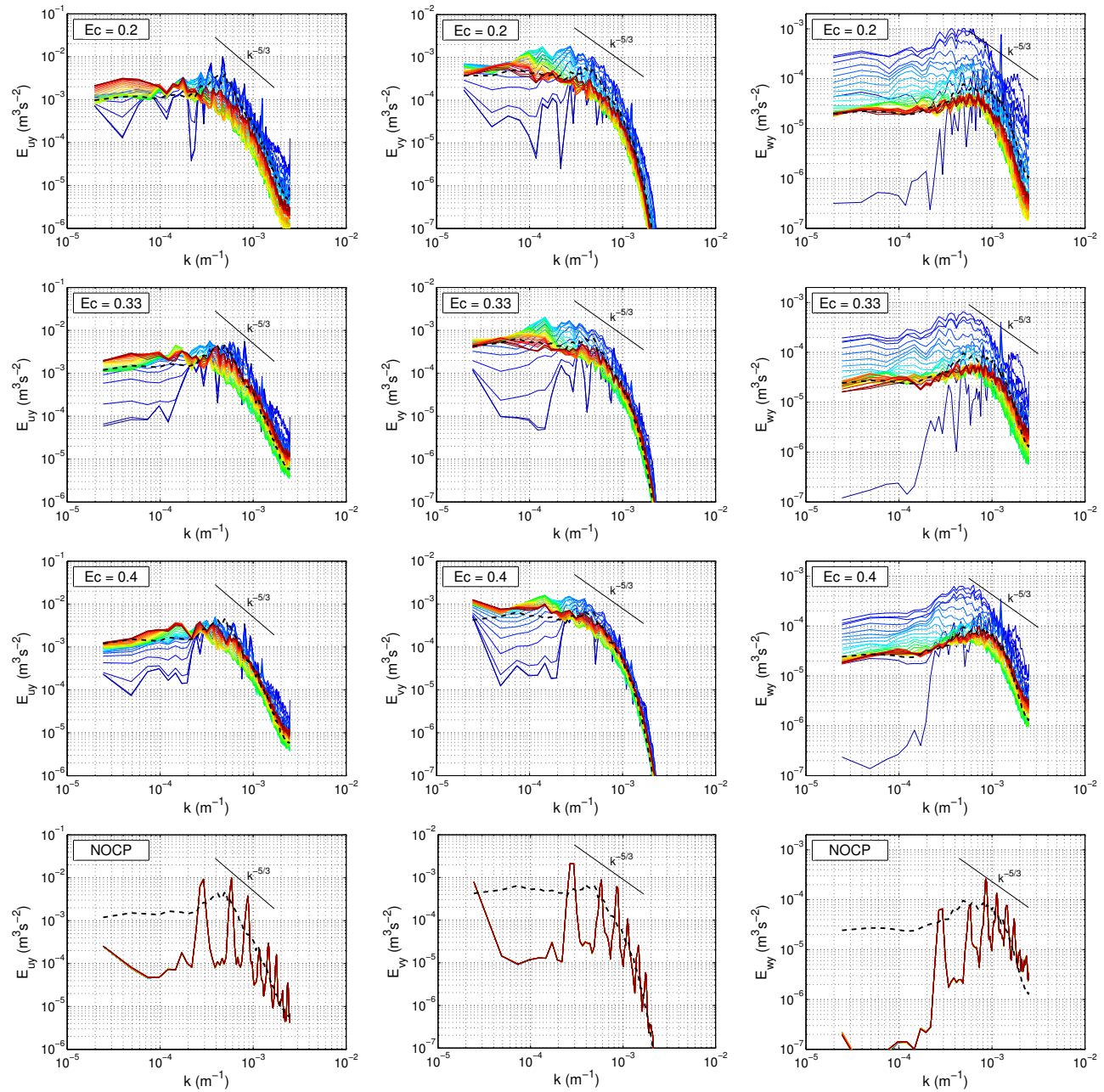

Figure 6. Spatial evolution of time-averaged energy spectra of $u$ (left), $v$ (middle) and $w$ component (right) in the $y$ direction at $z / z_{i}=0.5$ for three perturbation Eckert numbers and the NOCP case. Color lines indicate distance from the east lateral boundary in steps of $0.8 \mathrm{~km}, 51.2$ : $-0.8: 1.6 \mathrm{~km}$, from blue to red. The dashed black line corresponds to the reference spectrum from the periodic computation, additionally averaged in the streamwise direction.

June 2013 case, mainly characterized by its strong tradewind inversion (INV) and stronger background trade winds compared to the REF case. Table 3 summarizes the settings for all simulations that deviate from the standard configuration in Tables 1 and 2.

\subsection{Boundary layer and cloud characteristics}

To get a qualitative impression of the local situation simulated by the LES model, Fig. 9 shows a three-dimensional snapshot of the temperature and humidity field as well as cumulus clouds with up- and downdrafts visualized by isosurface fields at 12:00 LT for the reference case. The daytime convection is clearly visible by multiple updraft cells distributed over the whole island area, which subsequently leads to the development of non-precipitating shallow cumulus clouds. Advection of heated air from the central and southern part of the island towards the west can be seen in the surface temperature field (which is meant as temperature of the lowest model layer in this context), whereas the cooler marine flow narrows the thermal wake toward the meridional center of the domain up to $40 \mathrm{~km}$ downwind. This effect is connected with an island-induced change in wind speed and direction. The change in the humidity profile can be observed in the vertical cut plane at the western model boundary. A large amount of moisture is transported vertically upwards in the central region where also occasional cumulus clouds are present. A few tens of kilometers away in the $y$ direction, dryer air from heights of $500-1000 \mathrm{~m}$ is mixed downward.

For further insight into flow dynamics, especially for the downwind region, Fig. 10 provides the vertical wind field at $z \approx z_{i} / 2$ for all four considered cases. Looking at the REF and INV case, several turbulent updraft bands with lengths 

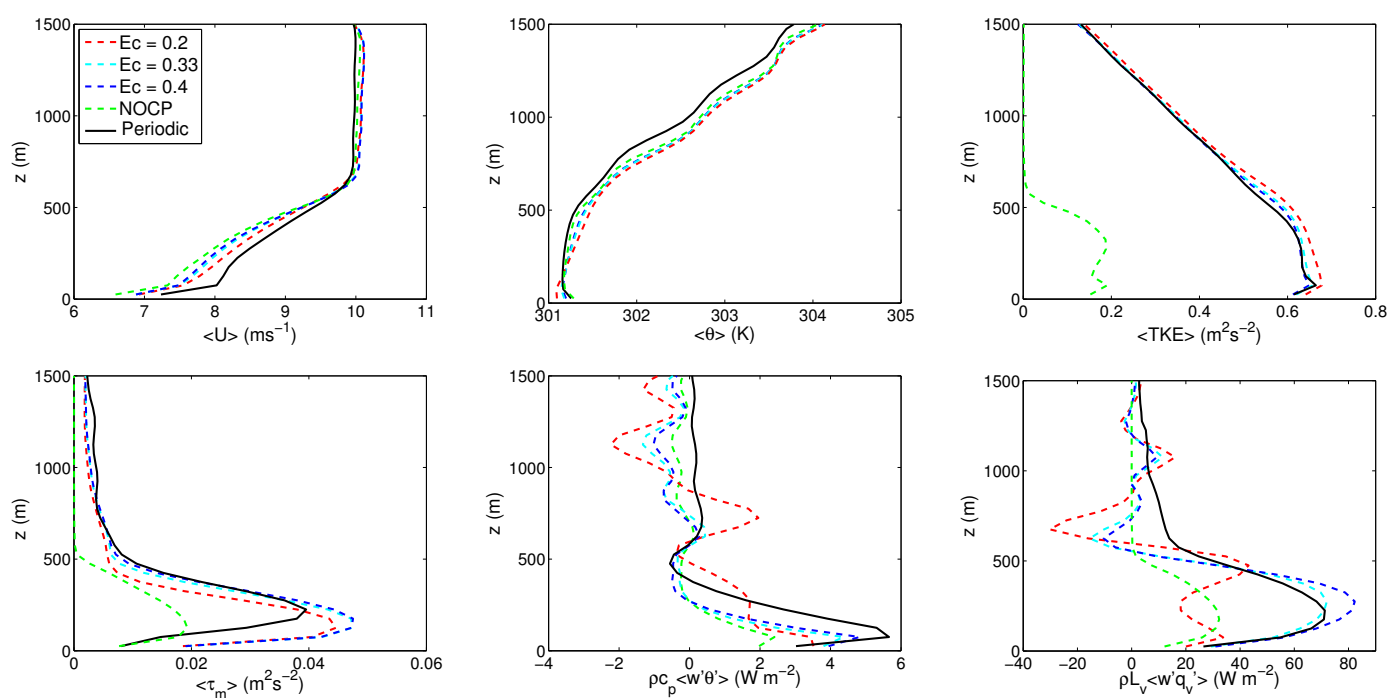

Figure 7. Vertical profiles of horizontal wind speed $\langle U\rangle$ (top left panel), potential temperature $\langle\theta\rangle$ (top middle), turbulent kinetic energy $\langle\mathrm{TKE}\rangle$ (top right), momentum flux $\left\langle\tau_{\mathrm{m}}\right\rangle$ (bottom left), sensible heat flux $\rho_{0} c_{\mathrm{pd}}\left\langle w^{\prime} \theta^{\prime}\right\rangle$ (bottom middle) and latent heat flux $\rho_{0} L_{0}\left\langle w^{\prime} q_{\mathrm{v}}^{\prime}\right\rangle$ (bottom right) at a downstream distance of $40 \mathrm{~km}$ from the east boundary for different Ec numbers and the NOCP case (averaged along the $y$ direction and in time). The solid black line corresponds to the reference profile from the periodic computation, additionally averaged in the streamwise direction. The profiles are valid for the 22 June 2013 case.

Table 2. Parameter values of the cases to be examined: 22 June and 27 June 2013.

\begin{tabular}{llcc}
\hline Parameter & Unit & $\begin{array}{c}\text { 22 June } \\
2013\end{array}$ & $\begin{array}{c}\text { 27 June } \\
2013\end{array}$ \\
\hline Maximum geostrophic wind $\left|u_{\mathrm{g}}\right|$ & & 10.0 & 11.5 \\
Top altitude of trade-wind inversion $z_{\text {inv, }} \mathrm{t}$ & $\mathrm{m} \mathrm{s}^{-1}$ & 2200 & 2000 \\
Bottom altitude of trade-wind inversion $z_{\text {inv, b }}$ & $\mathrm{m}$ & 1600 & 1800 \\
Inversion strength $\mathrm{d} \theta_{\mathrm{v}} / \mathrm{d} z$ & $\mathrm{~m}$ & 5.67 & 13.89 \\
Surface pressure $p_{0}$ & $\mathrm{~K} \mathrm{~km}^{-1}$ & 1014.2 & 1013.9 \\
Integrated water vapor content up to $z=2 \mathrm{~km}$ & $\mathrm{~kg} \mathrm{~m} \mathrm{~kg}^{-1}$ & 22.14 & 26.16 \\
CCN concentration at $1 \%$ supersaturation $N_{\mathrm{CCN}, 1 \%} \%$ & $\mathrm{~cm}^{-3}$ & 300 & 300 \\
Top altitude of Saharan dust layer & $\mathrm{m}$ & 2800 & 2900 \\
Bottom altitude of Saharan dust layer & $\mathrm{m}$ & 1800 & 1700 \\
\hline
\end{tabular}

of about $10 \mathrm{~km}$ in the zonal direction and vertical velocities up to $2.5 \mathrm{~m} \mathrm{~s}^{-1}$ develop all over the island area. However, one main band at $y \approx 52 \mathrm{~km}$ remains persistent, even at higher altitudes. This updraft band is a result of the dynamic and thermal instability over the island, forming quasi twodimensional horizontal vortex rolls with their axes aligned in the downwind direction (e.g. Etling and Brown, 1993). Toward the evening, as the surface sensible heat flux is not positive anymore and convection fades away, the band decouples from the island and vanishes (not shown). Turbulent updraft cells within the marine boundary layer with vertical velocities between 0.5 and $1 \mathrm{~m} \mathrm{~s}^{-1}$ are also visible since a turbulent inflow is generated with the cell perturbation method described in Sect. 2.5. In the INV case, these updrafts are a bit weaker, which is most likely due to the stronger mean horizontal wind speed. Wave-like structures in the upwind verti- cal velocity field are observed in the NOCP case. There, the flow remains laminar in this region, and since no perturbation is applied but surface fluxes are present, these artificial convergence lines are forming. Note that this effect is not seen in the REF and INV case. This underscores the importance of having an explicit inflow turbulence generation when working on LES scales. Just by visibly comparing the "coarse" simulation DX400 with the other cases, it becomes apparent that there is a lot of structure loss in the vertical wind field. All up- and downdraft bands - even the main updraft band downwind - are almost perfectly aligned in the $x$ direction. This shows the importance of using a grid spacing that resolves the inertial subrange of the velocity spectrum (cf. Bryan et al., 2003). Note that with coarser grid spacings the orographical structures of the island are also less represented. 


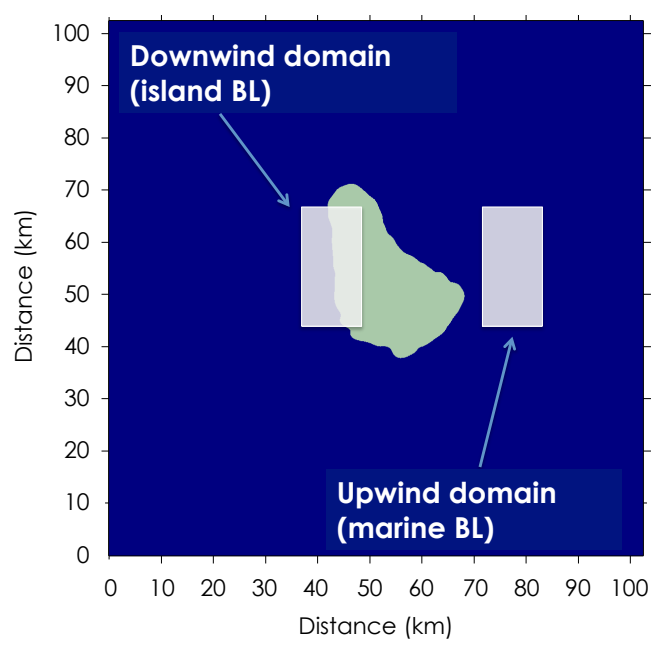

Figure 8. Definitions of subdomains for spatial averaging to cover different boundary layer characteristics: upwind marine regime east of Barbados (right) and downwind island regime over the west coast area (left).

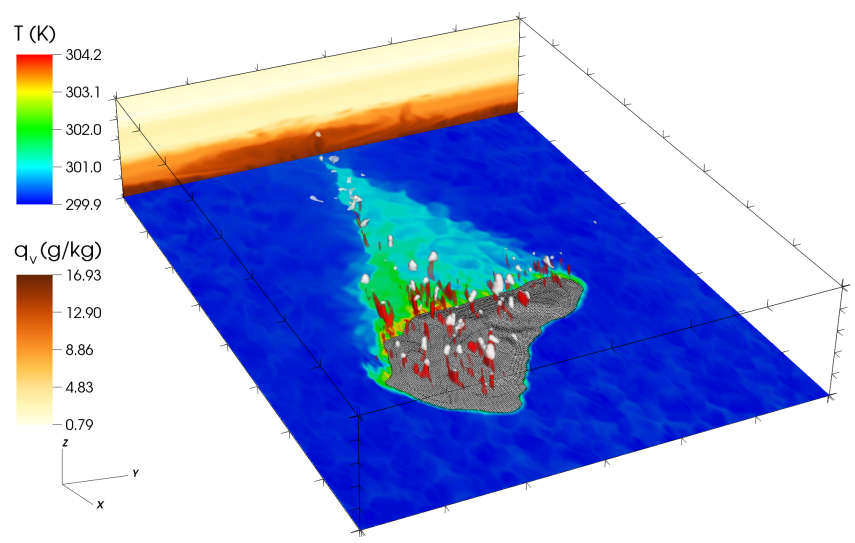

Figure 9. Perspective view of surface temperature and specific humidity field at the western boundary for the REF case. Clouds are visualized by $0.1 \mathrm{~g} \mathrm{~kg}^{-1}$ isosurface in white coloring. Red coloring depicts an isosurface of $2 \mathrm{~m} \mathrm{~s}^{-1}$ updrafts. Snapshot taken at 12:00 LT. A model area of $80 \mathrm{~km} \times 60 \mathrm{~km} \times 5 \mathrm{~km}$ is shown.

Figure 11 shows the surface wind fields and liquid water path for all simulated cases at 14:00 LT. In all these cases, the island convection affects both the strength (up to $4 \mathrm{~m} \mathrm{~s}^{-1}$ stronger wind speeds compared to marine surface winds) and direction $\left( \pm 30^{\circ}\right)$ of the wind in the downwind area of Barbados, thus leading to strong surface convergence and subsequently forming the updraft band as seen in Fig. 10 at $y=52 \mathrm{~km}$. Despite having this elongated band, very little cloud formation is observed in this area for the REF, NOCP and INV cases, which is also the case for other times of the day (not shown). This means that no continuous cloud street is modeled on 22 and 27 June 2013, respectively. While cloud streets occur on around $60 \%$ of undisturbed days, there are several effects that suppress cloud street generation (Kirsh-
Table 3. Parameter choices for the sensitivity simulations performed.

\begin{tabular}{llccc}
\hline $\begin{array}{l}\text { Simulation } \\
\text { name }\end{array}$ & Date & $\Delta x, \Delta y$ & $\Delta z$ & $\begin{array}{c}\text { Turbulent } \\
\text { inflow }\end{array}$ \\
\hline REF & $(\mathrm{m})$ & $(\mathrm{m})$ & \\
NOCP & 22 Jun 2013 & 200 & 50 & yes \\
2X Jun 2013 & 200 & 50 & no \\
INV & 22 Jun 2013 & 400 & 100 & no \\
\hline
\end{tabular}

baum and Fairman, 2015). In the REF (and NOCP) case, the relatively low moisture load $(\mathrm{RH}=80 \%$ near the surface, decreasing below $60 \%$ at $z \approx 1300 \mathrm{~m}$ ) and a weak tradewind inversion leads to a suppression of the development of a cloud trail. Both moisture and stratification are increased in the INV case but the stronger mean trade winds (almost $12 \mathrm{~m} \mathrm{~s}^{-1}$ ) are the suppressing factor here (Kirshbaum and Fairman, 2015). Due to the absence of a turbulent inflow velocity field, the cumulus clouds over the island are horizontally aligned to the mean wind direction in the NOCP case. In the REF and INV cases, more realistic scattered cumulus cloud fields over the island area and downwind are modeled. Besides the distinct cloud bands, the DX400 case shows further very notable differences in the cloud field. First of all, clouds are broader because of the coarser grid spacing. In addition to that, a continuous cloud street is modeled, which can be considered an artifact since such a cloud band is not seen in either other simulations or satellite observations. Furthermore, the downwind horizontal velocity field is slightly stronger compared to the other cases. We attribute this behavior to the lack of resolved small scales that cannot extract energy from the large eddies and therefore grow and become more coherent. This effect is also observed to a lesser extent for the NOCP case.

In the following, the diurnal development of the convective island boundary layer is investigated. Figure 12 shows time series of boundary layer and cloud properties for the downwind region around the west coast of Barbados. Further mean quantities of boundary layer and cloud characteristics are diagnosed and summarized in Table 4 . The REF and the INV case have some properties in common. They both show a strong increase in cloud cover in the downwind region between 07:00 and 08:00 LT up to a maximum value of about $16 \%$. The boundary layer height $z_{i}$ displays a diurnal variation, growing up to $z=1350 \mathrm{~m}$ around 13:00 LT in the REF case. For the INV simulation, $z_{i}$ is approximately $100-150 \mathrm{~m}$ shallower. This parameter is calculated via the bulk Richardson criterion, where the boundary layer height is defined as the height where the bulk Richardson number $R i_{\mathrm{b}}$ exceeds a value of 0.25 , with

$R i_{\mathrm{b}}=\frac{g}{\theta_{\mathrm{v} 0}} \frac{\theta_{\mathrm{v}}-\theta_{\mathrm{v} 0}}{u^{2}+v^{2}} z$ 

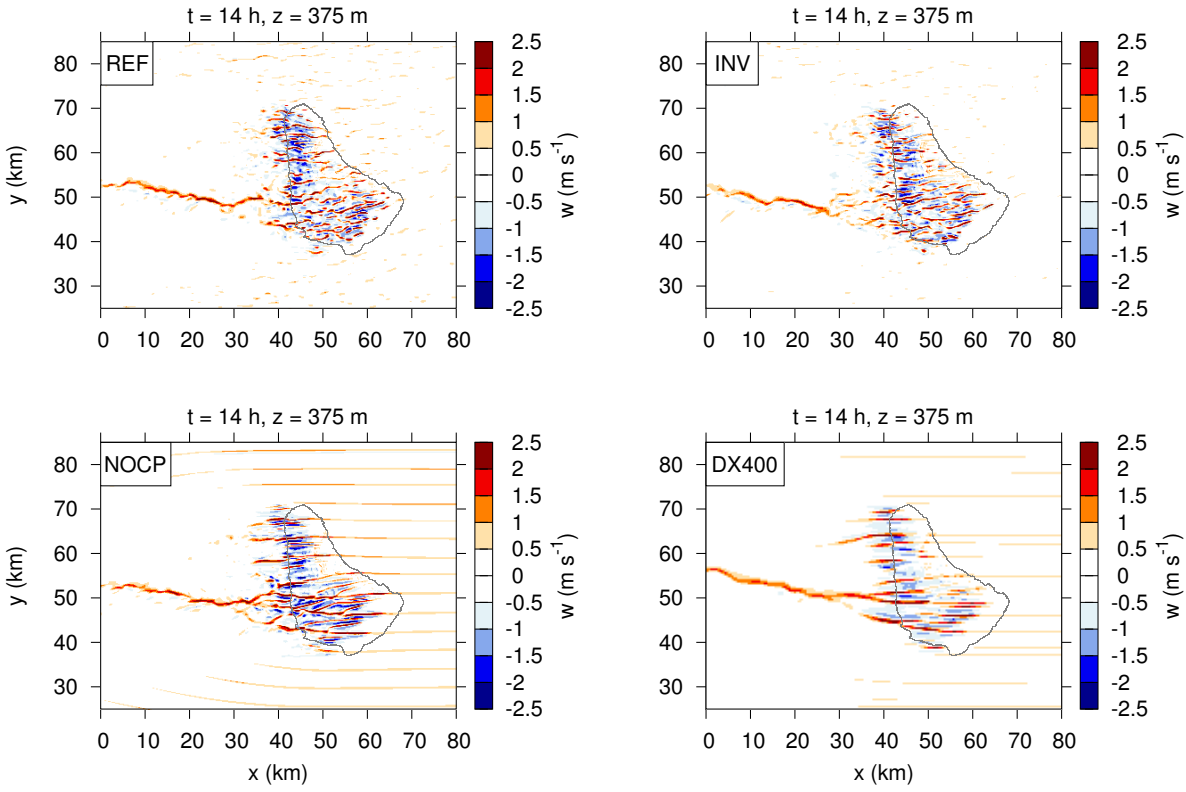

Figure 10. Vertical wind at $z=375 \mathrm{~m}$ a.s.1. at 14:00 LT for the four simulation cases (see Table 3).
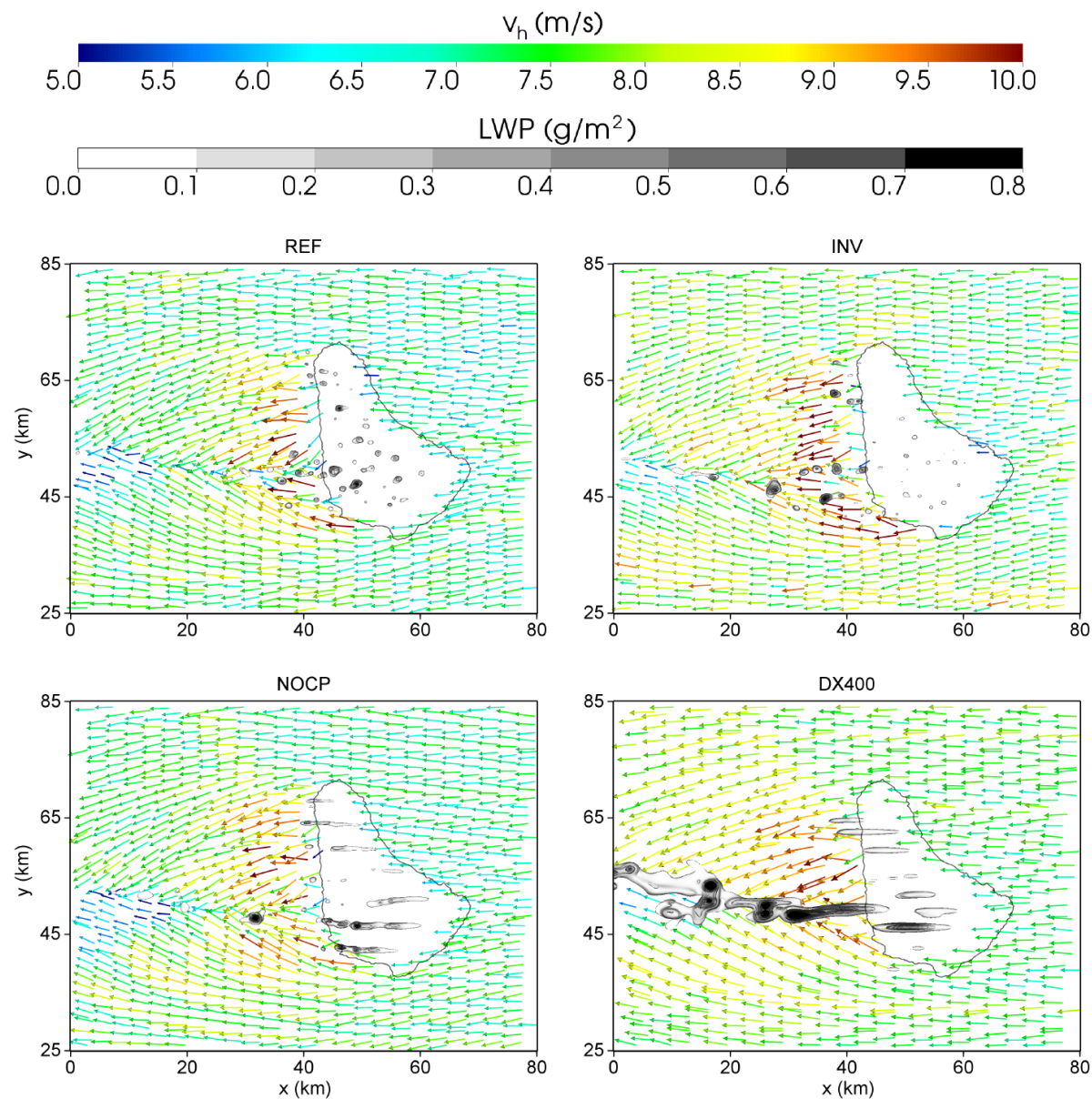

Figure 11. Horizontal cut planes ( $x y$ ) of surface wind vectors and contours of liquid water path for all four simulation cases (see Table 3 ). 


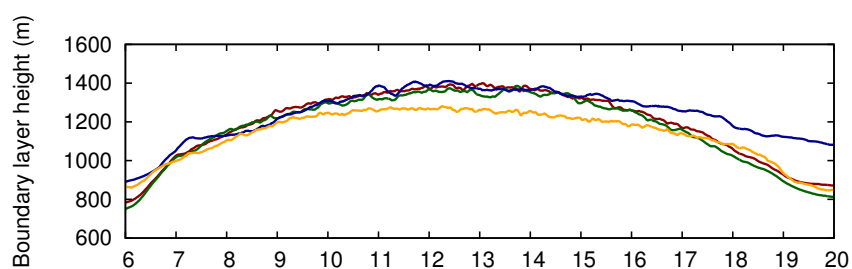

case has overall weaker peak updrafts; however, this does not mean that there is less vertical transport of energy, moisture, momentum etc. Due to the coarser grid spacing in every spatial direction there is a higher net upward transport.

To further investigate daytime-dependent vertical mixing and layering, Fig. 13 shows hourly averaged vertical profiles boundary layer and cloud parameters for the downwind domain compared to the daily upwind average. Comparing again the REF and INV cases, daytime-dependent differences in the density potential temperature and specific humidity profiles can be noticed (not shown). Lower levels at $z<700 \mathrm{~m}$ are warmer and dryer compared to the marine background. The vertical turbulent transport is evidenced by the profiles of sensible and latent heat fluxes. The sensible heat flux is linearly decreasing within the mixing layer up to heights between $700 \mathrm{~m}<z<900 \mathrm{~m}$, depending on the time of day. The maximum latent heat fluxes occur between $600 \mathrm{~m}<z<800 \mathrm{~m}$. Above that layer, the cloud water content reaches its maximum, which is connected to latent heat release and thus to an increase in the sensible heat flux and a decrease in the latent heat flux. In the INV case, the trade inversion around $z \approx 2000 \mathrm{~m}$ inhibits further cloud development above this height, whereas in the REF simulation there is also a notable amount of cloud water above $2000 \mathrm{~m}$. The presence of wind shear above $1500 \mathrm{~m}$ height leads to a secondary maximum of TKE around $z=2000 \mathrm{~m}$, which is not the case in the shearless INV simulation.

In the NOCP case, i.e., without a turbulent inflow, persistent updraft bands form over the island area, which is consistent with the modeled cloud field from Fig. 11. The inflow characteristics have little effect on boundary layer properties like TKE, vertical velocity variance (not shown), sensible and latent heat flux (cf. Fig. 13). However, the values for the NOCP case tend to be a bit higher than in REF, especially between 500 and $700 \mathrm{~m}$. One reason for this could be that the upwind marine boundary layer already vertically transported some amount of energy, which is missing in the NOCP case. More remarkable differences are noticeable with regard to cloud development. The LWC around $z \approx 1000 \mathrm{~m}$ during noon is nearly doubled for the NOCP case. There is also a particularly pronounced secondary maximum of LWC around $z \approx 2100 \mathrm{~m}$ in the same order of magnitude. With the average over the whole daytime period taken, the mean LWP is more than doubled in the NOCP case compared to the REF case, which is in agreement with higher LWC values and also higher cloud cover $(\approx+3 \%)$.

More undesired effects become apparent when using a coarser spatial resolution as in the DX400 case, which is most noticeable in the averaged vertical profiles. First of all, there is less variability in the potential temperature and specific humidity fields for altitudes $z>1000 \mathrm{~m}$, which can be explained by the lack of turbulent vertical transport within the boundary layer (this effect can be seen in the vertical profile of TKE in Fig. 13 and in the profile of the vertical velocity variance). The LWC, however, has maximum val- 
Table 4. Diagnostics the four sensitivity simulations (see Table 3), including cloud cover, cloud base height $z_{\mathrm{cb}}$, cloud top height $z_{\mathrm{ct}}$, boundary layer height $z_{i}$, water vapor path (WVP), liquid water path (LWP), and maximum updraft values $w_{\max }$. All quantities are spatially averaged for the downwind area and temporally averaged between 06:00 and 18:00 LT.

\begin{tabular}{lccccccc}
\hline Case & $\begin{array}{c}\text { Cloud cover } \\
(\%)\end{array}$ & $\begin{array}{c}z_{\mathrm{cb}} \\
(\mathrm{m})\end{array}$ & $\begin{array}{c}z_{\mathrm{ct}} \\
(\mathrm{m})\end{array}$ & $\begin{array}{c}z_{i} \\
(\mathrm{~m})\end{array}$ & $\begin{array}{c}\text { WVP } \\
\left(\mathrm{kg} \mathrm{m} \mathrm{kg}^{-1}\right)\end{array}$ & $\begin{array}{c}\text { LWP } \\
\left(\mathrm{g} \mathrm{m}^{-2}\right)\end{array}$ & $\begin{array}{c}w_{\max } \\
\left(\mathrm{m} \mathrm{s}^{-1}\right)\end{array}$ \\
\hline REF & 7.8 & 967 & 1167 & 1240 & 27.6 & 8.5 & 5.0 \\
NOCP & 11.0 & 1066 & 1269 & 1222 & 27.7 & 18.8 & 5.2 \\
DX400 & 9.7 & 1029 & 1237 & 1262 & 29.3 & 19.0 & 3.7 \\
INV & 8.6 & 846 & 1024 & 1174 & 33.2 & 5.9 & 4.5 \\
\hline
\end{tabular}

ues of $0.028 \mathrm{~g} \mathrm{~m}^{-3}$ around $z \approx 2000 \mathrm{~m}$, which is a factor of 2 higher compared to the REF case. This is accompanied by strong latent heat fluxes in these layers. Cloud growth is also more inhibited at finer resolutions due to explicit entrainment of dryer environmental air (e.g. Bryan et al., 2003). Having a distinct and quite symmetric diurnal variation in boundary layer and cloud properties in the other cases, the evening transition in the DX400 case is poorly represented, where still a notable number of clouds exist and a deeper boundary layer is modeled around 20:00 LT.

\subsection{Vertical mixing of aerosols}

After the long-range transport of Saharan dust into the Caribbean region, these dust layers arrive at Barbados with mean base heights of about $1.5-2 \mathrm{~km}$ a.s.l. Due to a possible interaction with the convective island boundary layer, vertical mixing of aerosols is investigated in this subsection. As already shown in Sect. 2, these aerosol layers are represented by passive tracers in the model. They are initialized with a relative concentration of 1 within the layer where the aerosol is detected and 0 otherwise. This approach has already been used for heat island effect studies in Engelmann et al. (2011). These relative concentrations can be related to mass concentrations of Saharan dust, e.g., $180 \mu \mathrm{g} \mathrm{m}^{-3}$. This mass concentration and the Saharan dust layer heights are estimated from ground-based multi-wavelength aerosol lidar measurements and provide a rough idea of the magnitude of these quantities. Especially the particle depolarization ratio indicates that the pure dust layer begins at around $1.5 \mathrm{~km}$ altitude. A detailed analysis of dust layers during the campaign can be found in Groß et al. (2015). Figure 14 displays height-distance profiles of the boundary layer tracer $\phi_{\mathrm{BLT}}$ and the Saharan dust tracer $\phi_{\mathrm{SDT}}$ near the west coast of Barbados. In both cases, the turbulent character over the island section is visible as a vertical distribution of the passive tracer within the higher boundary layer and the corresponding decrease in tracer concentration. It is more pronounced for the southern part of the island, which is due to the broader land area width $(20 \mathrm{~km}$ in the south compared to $10 \mathrm{~km}$ in the north). It also indicates the wind shear at the island boundaries (e.g., at $y=43 \mathrm{~km}$ ), which causes the advection of air masses from $z>700 \mathrm{~m}$ into the boundary layer. This effect is more pronounced further west (not shown). In the REF case, the mean boundary layer height around noon was calculated to be $z_{i} \approx 1400 \mathrm{~m}$. The passive tracer analysis additionally shows some local overshoots at heights over $2 \mathrm{~km}$ a.s.l. The Saharan dust tracers do have a different vertical structure. For the REF simulation, the tracer is thinned out, with maximum concentrations between $1.9 \mathrm{~km}<z<2.4 \mathrm{~km}$, whereas in the INV case it is between $1.7 \mathrm{~km}<z<2.5 \mathrm{~km}$. There are also no overshoots visible beyond $z=1.7 \mathrm{~km}$. The stronger turbulent mixing in the REF case can be explained by the presence of wind shear around $z \approx 1.5 \mathrm{~km}$ height, whereas in the INV case the strong trade-wind inversion suppresses further development of turbulence in higher altitudes. The logarithmic scale indicates the tracer diffusion, which shows that about $1 \%$ of the maximum concentration is present at altitudes between 1.3 and $1.5 \mathrm{~km}$ (depending on the case) and locally down to $1.0 \mathrm{~km}$ altitude due to the island effect.

Although there are already some indications of downward aerosol transport, a better quantification of these effects is still needed to achieve a better understanding of the processes behind it. For that reason, mean vertical profiles are calculated in the same manner as the boundary layer and cloud analysis. Figure 15 shows vertical profiles of tracerrelated quantities for the REF and the INV case. The tracer profile is being deformed by vertical transport processes, which can be originated by larger-scale or turbulent processes. To distinguish between those two, the total vertical tracer flux $\left\langle w \phi_{\mathrm{SDT}}\right\rangle$ and the turbulent vertical tracer flux $\left\langle w^{\prime} \phi_{\mathrm{SDT}}^{\prime}\right\rangle$ are computed. According to the model data, there is already a persistent downward movement east of Barbados between $1.5 \mathrm{~km}<z<3.0 \mathrm{~km}$, which corresponds to a subsidence velocity of $w=-407 \mathrm{mday}^{-1}$ for the REF case and $w=-345 \mathrm{mday}^{-1}$ for the INV case. There is a total relative downward flux for the downwind area in the REF case at $1.2 \mathrm{~km}$ height, with a maximum magnitude of $\left\langle w \phi_{\mathrm{SDT}}\right\rangle=$ $-0.03 \mathrm{~m} \mathrm{~s}^{-1}$. The height of this local extremum depends on the time of day, with higher altitudes in the morning and around noon and lower altitudes toward the evening. A net positive upward flux is always present above $z=2 \mathrm{~km}$, becoming zero at $z=3 \mathrm{~km}$. About one-third to one-half of the total downward flux is caused by turbulent mixing, having its local maxima at $z=1.8 \mathrm{~km}$, which is the lower bound of the 


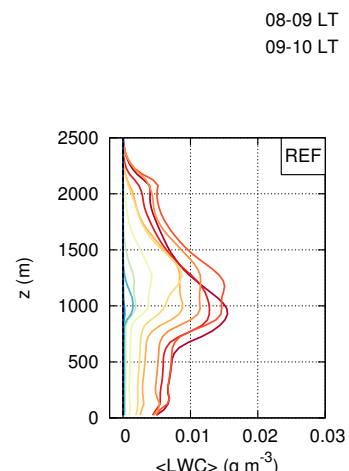

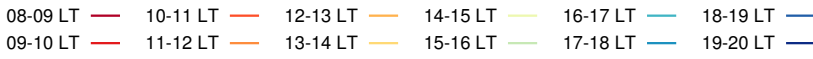
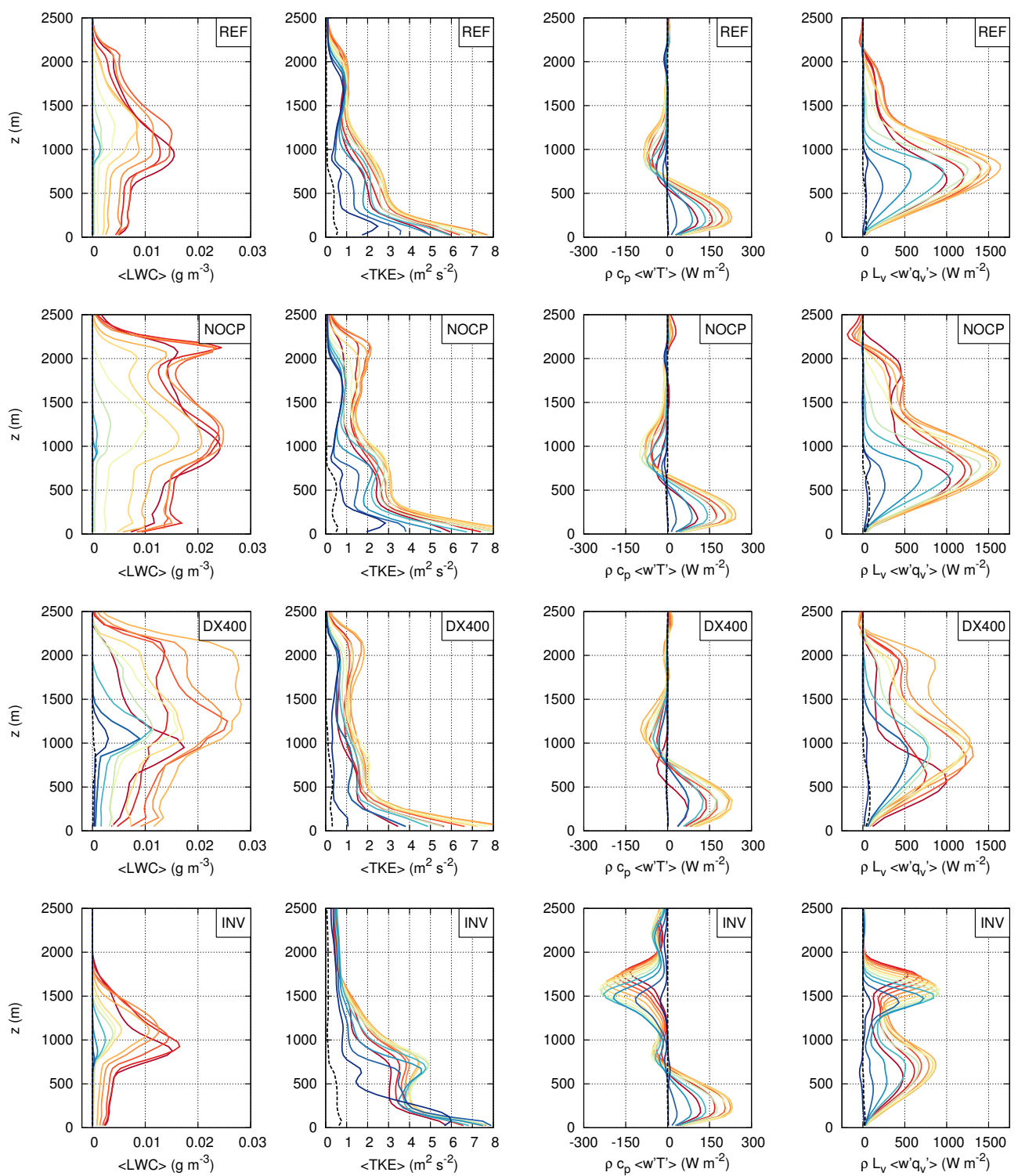

Figure 13. Vertical profiles of liquid water content $\langle\mathrm{LWC}\rangle$, resolved turbulent kinetic energy $\langle\mathrm{TKE}\rangle$, sensible and latent heat flux $\rho_{0} c_{\mathrm{pd}}\left\langle w^{\prime} T^{\prime}\right\rangle$ and $\rho_{0} L_{0}\left\langle w^{\prime} q_{\mathrm{V}}^{\prime}\right\rangle$ for all four considered cases (REF, NOCP, DX400 and INV from top to bottom). Spatial averaging as indicated in Fig. 8. Black dashed lines represent the marine upwind area and are temporally averaged between 08:00 and 20:00 LT. Colored solid lines represent for hourly averages during different times of the day for the downwind area.

Saharan dust layer. The daytime turbulent downward mixing is about 5 times stronger in the INV case but is shifted approximately $400 \mathrm{~m}$ toward the surface compared to REF. Due to the tracer subsidence, the layer also reaches these altitudes of maximum turbulent downward mixing, which would not be the case if the dust layer remained at its initial height of $1.7 \mathrm{~km}$. The downwind total tracer flux, however, is positive (upwards) for all altitudes and is almost 1 order of magnitude stronger compared to REF. Since the mean wind speed only slightly differs between the two cases and surface fluxes are the same, it can be concluded that atmospheric stability (especially inversion strength) and the presence of wind shear in the sub-inversion layer have a major impact on altitude and strength of layers with preferably upward or downward mixing properties. The model data suggest that the net effect, i.e., effects from both mean transport and turbulent mixing, is downward transport around the dust layer base for the downwind region in REF and a net upward transport in INV. 


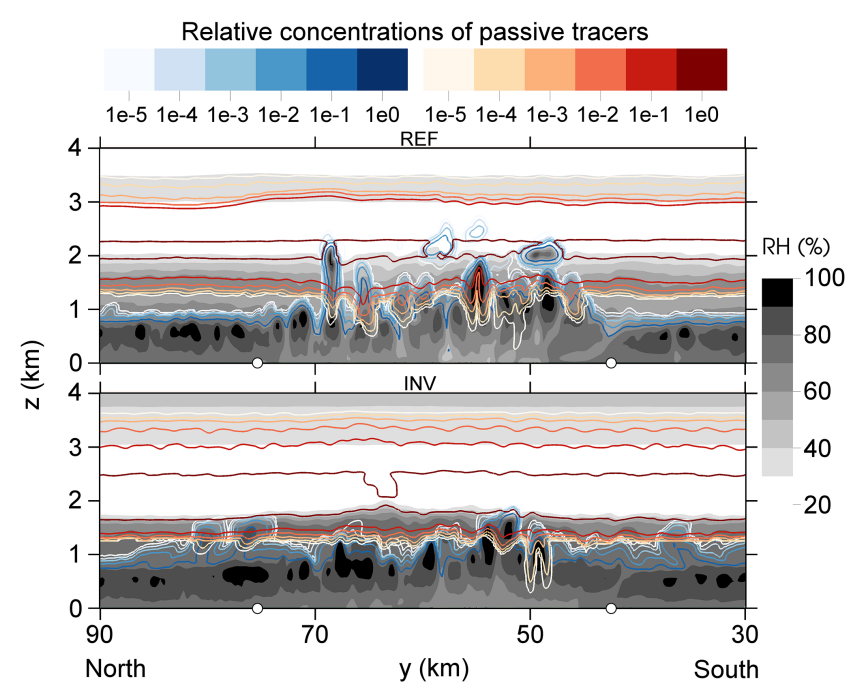

Figure 14. Meridional cut planes $(y-z$ profiles, $3 \mathrm{~km}$ off the west coast of Barbados) of the relative passive tracer concentrations and relative humidity for the REF (top panel) and the INV case (bottom panel). Red/orange contour coloring represents the Saharan dust tracer concentration $\phi_{\mathrm{SDT}}$ and blue contour coloring represents the boundary layer tracer concentration $\phi_{\mathrm{BLT}}$ on a logarithmic scale. White circles denote the location of the northern and southern island edges. The snapshots are taken at 12:00 LT.

\section{Comparison with lidar data}

\subsection{Doppler wind lidar: velocity fields}

In order to qualitatively evaluate the results obtained by the LES model, a comparison with the measurements performed by an airborne Doppler wind lidar (DWL) is presented in this section. Vertical and horizontal wind speed measurements from a flight on 20 June 2013 are compared to the simulation results of the 27 June 2013 case. A simulation with initial data at 20 June 2013 could not have been performed because no nighttime radiosonde data were available on this particular day. Although the measurements and the simulation correspond to different days, the comparison of the radiosonde profiles used for the LES initialization launched on 27 June and the dropsonde measurements obtained during the measurement flight on 20 June show a good agreement in the altitude of the trade inversion, relative humidity levels and temperature profile (Fig. 16). Especially the measured horizontal wind speed profile from the dropsondes matches better to the 27 June than the 22 June simulation case.

The airborne DWL used for this comparison was deployed onboard the DLR Falcon 20 research aircraft during the SALTRACE campaign. The system, based on an instrument developed by Lockheed Martin Coherent Technologies and enhanced by DLR to provide airborne measurement capabilities, can be operated in either nadir-pointing mode or scanning mode (Reitebuch, 2012; Chouza et al., 2015). The nadirpointing mode allows the retrieval of vertical wind speeds with a vertical resolution of $100 \mathrm{~m}$ and a horizontal resolution of approximately $200 \mathrm{~m}$ with a random error lower than $0.15 \mathrm{~m} \mathrm{~s}^{-1}$ and a systematic error lower than $0.05 \mathrm{~m} \mathrm{~s}^{-1}$. Note that these resolutions are almost identical to the grid spacings used in the LES. The overflight took place between 10:36 and 10:44 LT at a flight altitude of $2900 \mathrm{~m}$.

Figure 17 shows the flight track corresponding to the overflight (plane 2 in the figure) together with the LES results of the vertical wind speed for the 27 June case at 10:30 LT. For this overflight, vertical wind measurements on the lee side and over the island are available.

A comparison between the measured and the simulated vertical wind speed profiles is displayed in Fig. 18, where some main structures can be recognized in both profiles. Strong vertical winds associated with convective activity over Barbados can be observed in both the simulation and the measurements. In the case of the measurements, the presence of convective clouds limits the lidar coverage over the island (between 47 and $63 \mathrm{~km}$ on the $x$ axis). For the measurements performed on the lee side of Barbados and for altitudes above $1 \mathrm{~km}$ a series of waves with a wavelength of approximately $10 \mathrm{~km}$ and an amplitude of $2 \mathrm{~m} \mathrm{~s}^{-1}$ can be recognized. A similar feature can be seen in the LES data, but with a slightly weaker amplitude.

To get a better idea of the horizontal distribution of these waves at a certain level, Fig. 19 shows the vertical wind speed at the trade-wind inversion height for different times during the day. It seems that the strength of daytime convective activity plays a minor role since the overall pattern looks very similar in all three snapshots, with the exception of minimally stronger fluctuations toward the afternoon hours. A marked wave structure in the lee of the island is visible, which is the result of trapped gravity waves due to the strong inversion. Again, a similar wavelength amplitude of about $10 \mathrm{~km}$ can be seen and stronger amplitudes (comparable to the DWL measurements) originating from the northern part of Barbados are also visible.

Figure 20 shows a comparison between the mean and the variance of the measured and simulated vertical wind speed on the lee side (between 0 and $35 \mathrm{~km}$ on the $x$ axis) of Barbados. The mean vertical wind profiles of the measurements (black line) show a reasonable agreement with the LES results regarding the overall structure (e.g., cut planes 1,2 and 5, which are located at the southern and northern edge of Barbados, covering a similar spatial area as in the flight route). The mean vertical velocity below $1 \mathrm{~km}$ height indicates a downdraft region on the lee side of Barbados. This can be explained by the daytime circulation pattern in the lee of Barbados since the updraft band located between the center and southern part of the island causes downdrafts at its lateral flanks. Planes 3 and 4 reflect this behavior with positive vertical velocities below $1 \mathrm{~km}$ height. The variance of the vertical wind field shows an overall increase with altitude both for measurement and model results. However, the strength of these fluctuations is increased in the measurement 

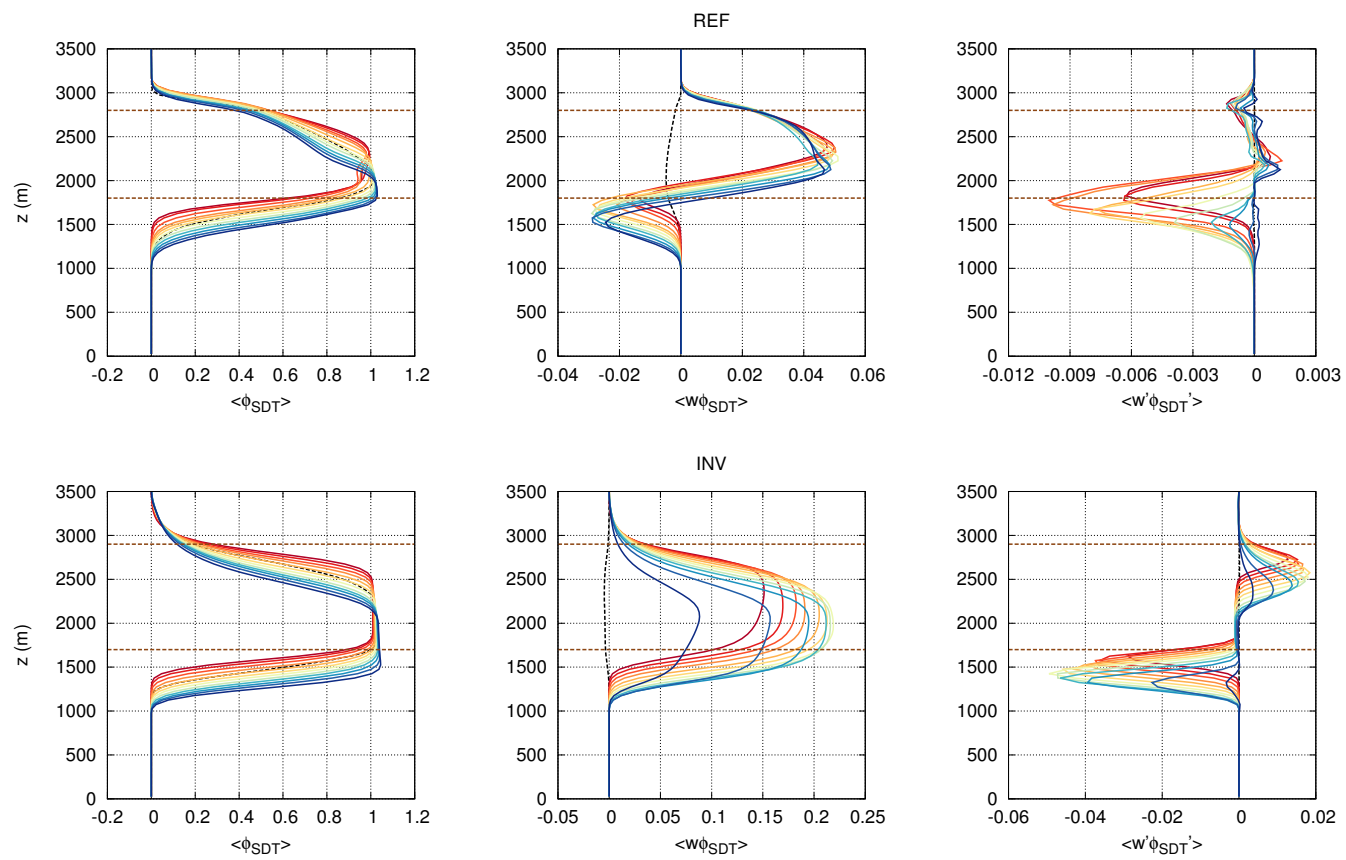

Figure 15. Vertical profiles of the passive Saharan dust tracer $\left\langle\phi_{\mathrm{SDT}}\right\rangle$ (left panel), the total vertical tracer flux $\left\langle w \phi_{\mathrm{SDT}}\right\rangle$ (middle panel) and the resolved turbulent tracer flux $\left\langle w^{\prime} \phi_{\mathrm{SDT}}^{\prime}\right\rangle$ (right panel) for the REF case (top row) and the INV case (bottom row). Solid line colors and spatial as well as temporal averaging as in Fig. 13. The horizontal brown dashed line represents the initial location of the Saharan dust tracer between $1800 \mathrm{~m} \leq z \leq 2800 \mathrm{~m}$ for REV and between $1700 \mathrm{~m} \leq z \leq 2900 \mathrm{~m}$ for INV.
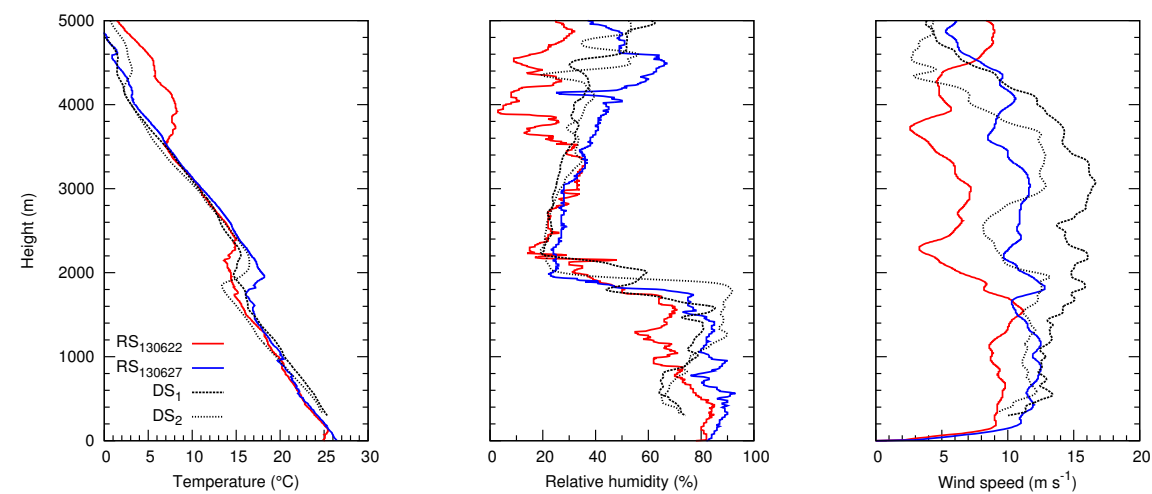

Figure 16. Comparison of measured temperature (left panel), relative humidity (middle panel) and wind speed (right panel) obtained from the nighttime radiosonde launches (solid lines) on 22 June (red curve) and 27 June (blue curve) and two dropsonde profiles during the wind lidar measurements at 20 June onboard the Falcon aircraft. DS 1 (dashed lines) was launched 100 km to the west of Barbados at 12:46:59 UTC and $\mathrm{DS}_{2}$ (dotted lines) was launched $200 \mathrm{~km}$ to the east of Barbados at 13:22:51 UTC.

data, which could result from differences in the forcing, e.g., stronger surface fluxes than the prescribed ones in the LES model.

\subsection{Multi-wavelength Raman lidar: convective boundary layer structure}

A stationary lidar system deployed at the CIMH during the SALTRACE campaign was the polarizing Raman lidar BERTHA (Backscatter, Extinction, lidar Ratio, Temperature, Humidity profiling Apparatus; Tesche et al., 2011). Contin- uous measurements were performed on 22 June 2013 from 09:49 to 17:23 LT and after sunset (around 18:30 LT) from 19:32 to $22: 30$ LT.

The range-corrected signal for the $532 \mathrm{~nm}$ cross polarized channel is shown in the top panel of Fig. 21. The vertical resolution is $7.5 \mathrm{~m}$ and the time resolution varies from 3 to $15 \mathrm{~s}$. The mean wind speed $(<3 \mathrm{~km}$ altitude) was approximately $10 \mathrm{~m} \mathrm{~s}^{-1}$, which results in a horizontal resolution of 30 to $150 \mathrm{~m}$. A first strong dust layer in a very dry environment (20-30\% RH) was detected between 1.8 and $2.8 \mathrm{~km}$, topped 


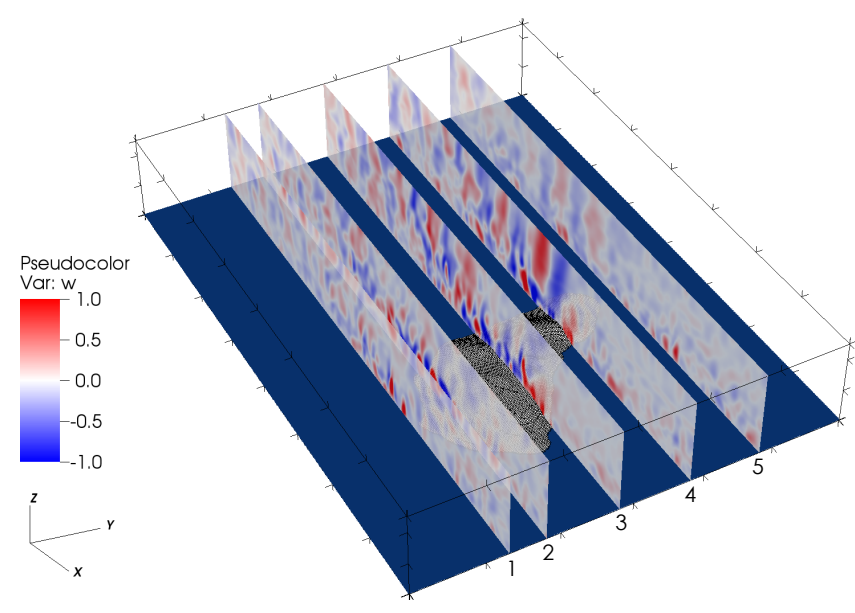

Figure 17. Locations of the five considered vertical planes for the comparison between the LES results and the DWL measurements within a domain of $60 \mathrm{~km}(y)$ and $80 \mathrm{~km}(x)$ up to an altitude of $2.5 \mathrm{~km}(z)$. The vertical wind (in $\mathrm{m} \mathrm{s}^{-1}$ ) along the planes is indicated in red (updrafts) and blue (downdrafts). Plane 2 is similar to the Falcon flight track. Planes 1 and 5 have no intersection with the island area, which is visualized by surface cut cells of the computational grid. Ocean area is in blue.
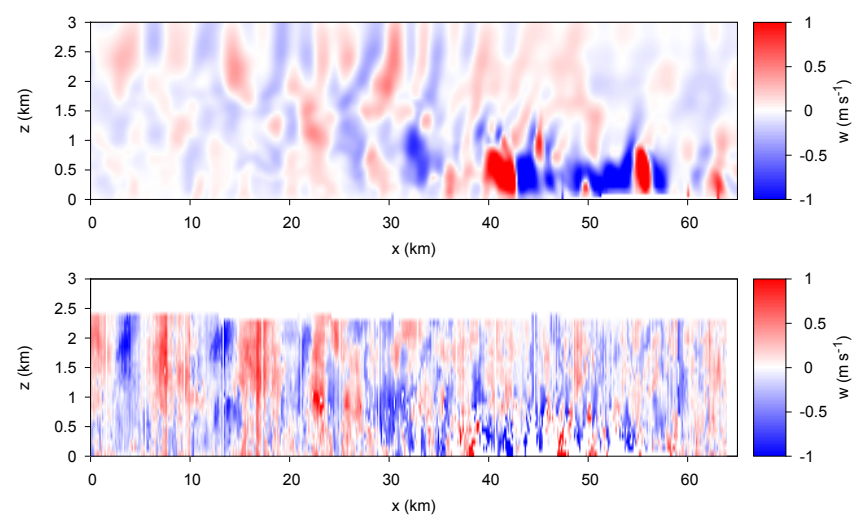

Figure 18. LES model output of zonal height-distance profiles of vertical wind speed component (upper panel) at 10:30 LT. DWL vertical wind speed component (lower panel) between 10:36 and 10:44 LT. Location indicated in Fig. 17. Island area is between $47 \mathrm{~km}<x<63 \mathrm{~km}$.

by a second, weaker dust layer between 2.8 and $3.7 \mathrm{~km}$ which was more humid (40-50\% RH). Temperature inversions set the limits of the total dust layer or Saharan Air Layer. The lidar signal shows clouds all over the day around $1 \mathrm{~km}$ height and close to $1800 \mathrm{~m}$. On average, 20 clouds per hour cross the lidar beam with an increasing number in the afternoon, leading to a cloud cover (in this context defined on a temporal scale) of roughly $50 \%$. At nighttime only a single cloud was detected within $3 \mathrm{~h}$ of measurement, which confirms the convective character of the daytime clouds at the investigated day over the west coast of Barbados. The bottom panel in Fig.
21 shows the LES model output of the corresponding heighttime profile of relative humidity for this day and the same location. The diurnal variation in convective vertical moisture transport is clearly pronounced. Clouds (white/red coloring) develop at the same altitudes as in the BERTHA lidar measurements. Even higher and deeper clouds up to the top of the trade inversion at $z=2 \mathrm{~km}$ are resolved. Higher cloud activity can be noticed in the measurements, whereas the LES model results show fewer clouds toward the late afternoon. This effect can be attributed to the relatively low ocean latent heat flux from the marine boundary layer forcing, which tends to dry out the lower troposphere over a longer period of time (i.e., toward the afternoon and evening hours). Additionally, there is a notable increase in moisture during the afternoon (see the 16:01 LT radiosonde launch compared to the other ones) within the first $800 \mathrm{~m}$ of the lower troposphere. Because of the fact that no additional large-scale forcing (in this case, advection of moist air) is applied during the simulation time, this effect expectedly cannot be captured by the LES.

Further comparisons regarding the cloud base height are conducted, revealing an even better agreement between the BERTHA lidar measurements and the model results. Figure 22 shows the temporal evolution of the cloud base height derived from the REF case LES output and the cloud base height derived from BERTHA lidar measurements during 22 June 2013. The cloud base was detected from the lidar signal with an accuracy of $\pm 50 \mathrm{~m}$. The algorithm sets the cloud base if the $52.5 \mathrm{~m}$ vertically smoothed $532 \mathrm{~nm}$ total signal increases by a factor of 2 within $50 \mathrm{~m}$. To get an overview of the day, the temporal resolution was set to $30 \mathrm{~s}$. This procedure reproduces the temporal cloud evolution in Fig. 22. The spread gives an idea about the cloud thickness due to the fact that if a cloud overpasses the lidar beam, it is very likely that cloud water near the cloud top is detected at the beginning and/or at the end of the overpass. However, in some cases, it indicates some single clouds that start at an altitude of $1600 \mathrm{~m}$. At noon, the cloud base gets higher and the clouds are generally thinner, which can be seen the in range of variation in the lidar data, which is very low at this period of time. Overall, there is less variability in the LES data due to the spatial averaging over the downwind region.

\section{Conclusions}

We have presented a numerical study for investigating islandinduced effects on boundary layer structure, cloud generation and vertical mixing of aerosol layers at the easternmost Caribbean island of Barbados. The simulations were performed with the model ASAM on large eddy scale, where the horizontal resolution of $\Delta x=\Delta y=200 \mathrm{~m}$ is adequate to still resolve the lower wavenumber end of the inertial subrange of the turbulence spectrum. 

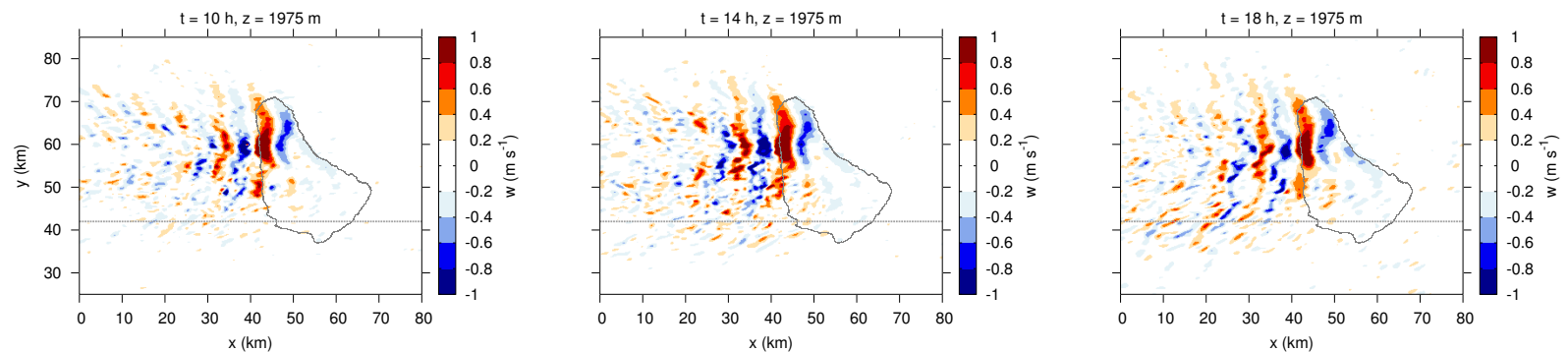

Figure 19. LES model output of vertical wind fields around the trade-wind inversion height at $z=1975 \mathrm{~m}$ at 10:00, 14:00 and 18:00 LT on 27 June 2013. The gray dashed line indicates the Falcon flight track (similar to cut plane 2 in Fig. 17).
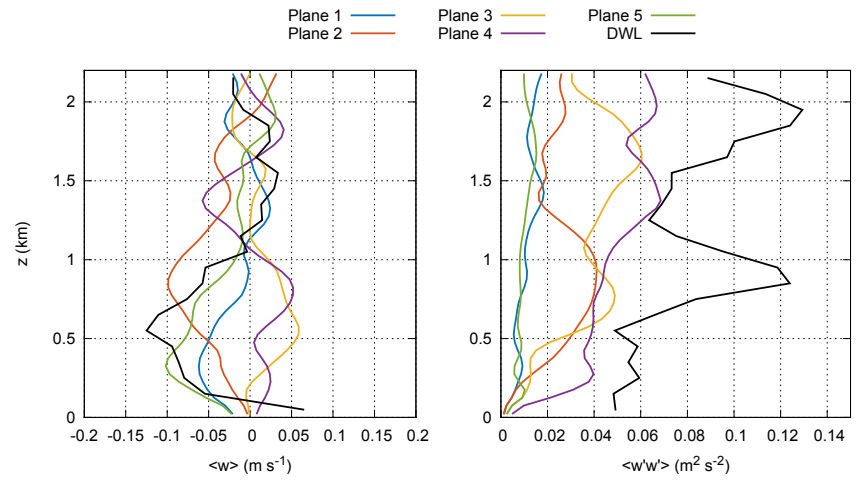

Figure 20. Comparison between the mean (left panel) and the variance (right panel) of the measured (black line) and simulated (colored lines) vertical wind fields at the lee side of Barbados at 10:30 LT. The wind profiles are horizontally averaged in the $x$ direction along the five different cut planes indicated in Fig. 17.

In order to generate inflow turbulence consistent with the upstream marine boundary layer forcing, the cell perturbation method based on finite amplitude perturbations was used. This method has been successfully adapted to moist boundary layer simulations with open lateral boundary conditions. Spectral analysis and examinations of vertical profiles of boundary layer quantities were used to determine the optimal Eckert number for the simulations. It was found that a value of $E c=0.4$ is most suitable for the island simulations, guaranteeing rapid development of turbulence that is very close to results from periodic BC simulations. This perturbation Eckert number differs from the optimum $E c=0.2$ derived for neutral stability (Muñoz-Esparza et al., 2015). These weaker-amplitude temperature perturbations appear to be due to a combination of the use of open boundary conditions and near production range grid resolution.

After the model was set up, several simulations were performed to analyze island effects. The atmospheric state is described by a horizontally homogeneous profile obtained via nighttime radiosonde launches. On the one hand, the used profile cannot be seen as a representative state, which could have been achieved by averaging multiple profiles. On the other hand, these quasi-idealized simulations en- abled the possibility to compare the LES output data with DWL measurements. Large-scale forcings are not applied during the simulation time, i.e., a time-invariant background state is used, which makes it easier to analyze daytime changes in boundary layer and cloud characteristics as a result of convective island activity. The radiosonde profile from 22 June 2013 served as a reference case for a crucial sensitivity study, which revealed the following:

- Disadvantages of neglecting a turbulent inflow and modeling within the "terra incognita" or "gray zone" become apparent (Wyngaard, 2004). If the turbulent inflow generation is turned off, i.e., no marine boundary layer develops, cloud properties are drastically changed over and in the lee of the island. There, cloud cover, liquid water path and cloud base height have significantly higher values compared to the reference case. Also, the cloud morphology is different, having horizontally aligned cloud bands instead of scattered cumulus clouds.

- Using a generally coarser horizontal grid spacing of $\Delta x=\Delta y=400 \mathrm{~m}$ shows the same issues regarding cloud properties. Additionally, boundary layer turbulence is not well resolved but vertical energy transport is enhanced overall, which leads to the formation of a cloud street along the updraft band past Barbados. This has not been seen in the other cases and can thus be considered an artificial effect.

- For the two considered cases (22 and 27 June 2013), analysis of the daytime convective boundary layer shows generally similar vertical profiles for both, although slight differences were detected due to wind shear effects in particular. Also, for the case with the strong trade inversion, the boundary layer grew approximately $150 \mathrm{~m}$ deeper. Significant differences were again visible in cloud properties. In the latter case, the trade inversion inhibited cloud growth beyond $1800 \mathrm{~m}$ altitude, whereas local overshoots through the weaker inversion occurred in the 22 June case.

Vertical mixing of aerosols, in our case Saharan dust layers, has been qualitatively and quantitatively analyzed by in- 


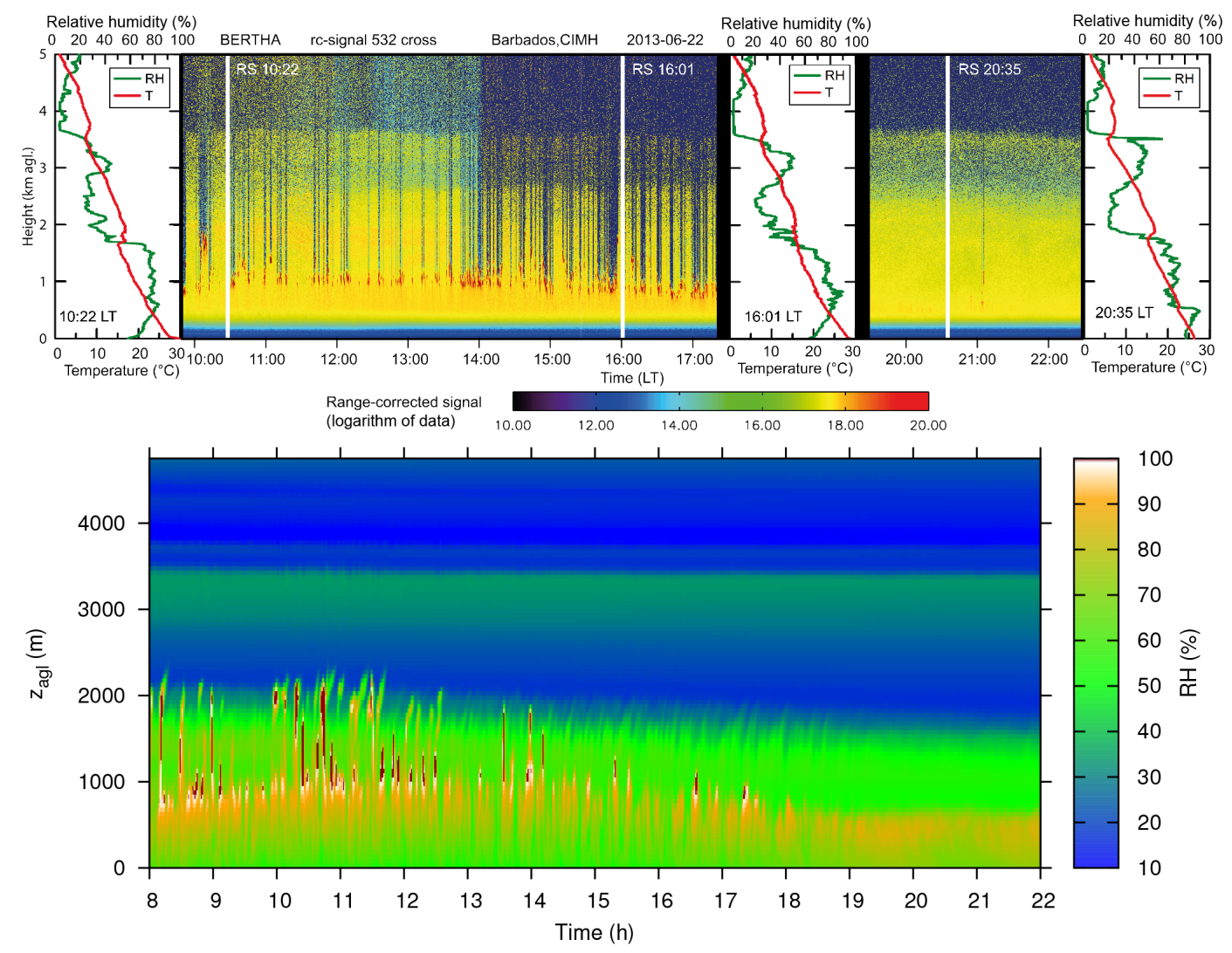

Figure 21. Top panel: BERTHA lidar measurements at CIMH and three radiosonde profiles of 22 June 2013. The range-corrected signal of the $532 \mathrm{~nm}$ cross-polarized channel is shown. The aerosol layer (in yellow) reaches up to $3.7 \mathrm{~km}$. The signal peaks (in red) are liquid clouds through which the lidar beam cannot penetrate, resulting in the lack of signal above the cloud. At 14:04 LT the temporal resolution was changed from $15 \mathrm{~s}$ to $3 \mathrm{~s}$. Bottom panel: LES model results of relative humidity at the CIMH grid point for the REF case, corresponding to 22 June 2013.

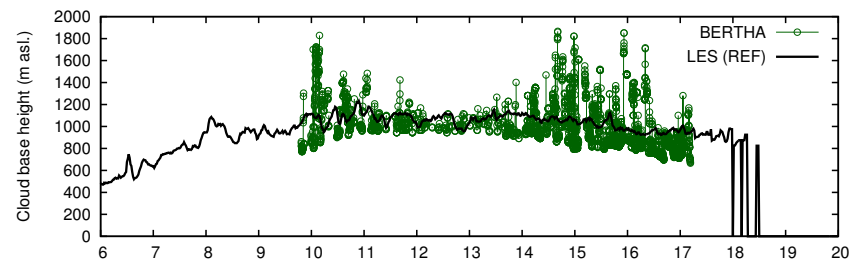

Figure 22. Temporal evolution of the spatially averaged cloud base height from the LES REF case (black line) and cloud base height derived from BERTHA lidar measurements (green circles) during 22 June 2013 at the west coast near the CIMH.

cluding passive tracers in the LES model. They are initialized at the same heights as they are seen in lidar data during the considered days. The model data suggested that a continuous subsidence velocity within these layers was present, which led to a mean sinking of $400 \mathrm{~m}$ toward the surface. Layers of turbulent downward mixing have also been detected between 1200 and $1700 \mathrm{~m}$ altitude. It can be concluded that if the dust layer reaches this height range, turbulent downward mixing of aerosol takes place, which is separated from large- scale subsidence effects. The exact position of these layers and the strength of downward turbulent mixing and transport are mainly controlled by atmospheric stability and wind shear. It became apparent that for the INV case the net direction of vertical transport is upwards for heights around the Saharan dust layer base. A larger number of simulation cases would provide further insight into this effect and the influence of trade inversion strength.

Qualitative comparisons with DWL measurements were carried out to validate the LES model results. A lot of similarities were found despite comparing different days, which, however, were very similar in terms of atmospheric stability, mean wind and temperature profile. First of all, large-scale changes in dynamics occur, which expectedly cannot be directly captured by the model. Furthermore, the vertical wind field shows a similar structure for both measurements and LES, highlighting the convective activity over the island and trapped gravity waves around the strong trade inversion. The amplitude of these waves was a bit higher in the measurements, which is also seen in the vertical wind variance profile. Taking these comparison results into account and con- 
necting them to the boundary layer and tracer analysis, it is possible that turbulent (downward) mixing of aerosol layers could be even more enhanced than the LES model results suggest.

From the stationary Raman lidar BERTHA, which was deployed near the west coast of Barbados, cloud base heights and thickness were estimated and compared with the LES data. With these two techniques combined, a consistent picture of the diurnal convective activity and cloud generation over the island was gained for the most part.

Possible future model development could focus on the direct and indirect aerosol effect as well as shadowing effects. This would lead to a better understanding of the effects of dust particles in connection with low-level clouds on their radiative feedback, e.g., as shown in Ge et al. (2014).

Furthermore, finer horizontal grid spacings than $200 \mathrm{~m}$ would be desirable to either confirm the robustness of the obtained results or reveal additional effects of finer resolved turbulent structures. This would lead to a better simulation of stably stratified areas, e.g., at the trade inversion. Also, it can be expected that, with a higher effective model grid resolution, the computed velocity variances would be closer to the measurement results of the Doppler lidar system. However, this requires a great deal of computational effort, especially when performing sensitivity tests with a larger number of simulations.

As a general conclusion of this work, the simulations performed provided a detailed image of downwind boundary layer structure, cloud and vertical mixing processes, which agree well with lidar measurements. The model data can also help to better interpret the ground-based observations gained during the SALTRACE campaign at the Barbados west coast (CIMH field site). 


\section{Appendix A: Numerical setup and model physics}

ASAM numerically solves the fully compressible flux-form Euler equations:

$$
\begin{aligned}
& \frac{\partial \rho}{\partial t}+\nabla \cdot(\rho \boldsymbol{v})=0, \\
& \frac{\partial(\rho \boldsymbol{v})}{\partial t}+\nabla \cdot(\rho \boldsymbol{v} \boldsymbol{v})= \\
& -\nabla \cdot \boldsymbol{\tau}-\nabla p-\rho \boldsymbol{g}-2 \boldsymbol{\Omega} \times(\rho \boldsymbol{v}), \\
& \frac{\partial(\rho \phi)}{\partial t}+\nabla \cdot(\rho \boldsymbol{v} \phi)=-\nabla \cdot \boldsymbol{q}_{\phi}+S_{\phi} .
\end{aligned}
$$

Here, $\rho$ is the total air density, $v=(u, v, w)^{\mathrm{T}}$ is the threedimensional velocity vector, $p$ is the air pressure, $g$ is the gravitational acceleration, $\boldsymbol{\Omega}$ is the angular velocity vector of the Earth, $\phi$ is a scalar quantity (representing energy and microphysical variables) and $S_{\phi}$ is the sum of its corresponding source terms. The subgrid scale (SGS) terms are $\boldsymbol{\tau}$ for momentum and $\boldsymbol{q}_{\phi}$ for a given scalar. The energy equation in the form of Eq. (A3) is represented by the density potential temperature $\theta_{\rho}$ (Emanuel, 1994):

$\theta_{\rho}=\theta\left(1+q_{\mathrm{v}}\left[\frac{R_{\mathrm{v}}}{R_{\mathrm{d}}}-1\right]-q_{\mathrm{c}}\right)$.

Hence, the air pressure can be diagnosed via the equation of state

$p=\rho R_{\mathrm{d}} \theta_{\rho}\left(\frac{p}{p_{0}}\right)^{\kappa_{\mathrm{m}}}$,

where $\theta=T\left(p_{0} / p\right)^{\kappa_{\mathrm{m}}}$ is the potential temperature, $q_{\mathrm{v}}=$ $\rho_{\mathrm{V}} / \rho$ is the mass ratio of water vapor in the air (specific humidity), $q_{\mathrm{c}}=\rho_{\mathrm{c}} / \rho$ is the mass ratio of cloud water in the air, $p_{0}$ is a reference pressure and $\kappa_{\mathrm{m}}=\left(q_{\mathrm{d}} R_{\mathrm{d}}+q_{\mathrm{v}} R_{\mathrm{v}}\right) /\left(q_{\mathrm{d}} c_{\mathrm{pd}}+\right.$ $\left.q_{\mathrm{v}} c_{\mathrm{pv}}+\left[q_{\mathrm{c}}+q_{\mathrm{r}}\right] c_{\mathrm{pl}}\right)$ is the Poisson constant for the air mixture (dry air, water vapor, cloud water, rain water) with $q_{\mathrm{d}}=\rho_{\mathrm{d}} / \rho . R_{\mathrm{d}}$ and $R_{\mathrm{v}}$ are the gas constants for dry air and water vapor, respectively. The Coriolis parameter $f=$ $2 \omega \sin \varphi=3.3 \times 10^{-5} \mathrm{~s}^{-1}$ is calculated from a latitude value of $\varphi=13.18^{\circ}$, with $\omega$ being the angular velocity of the Earth.

To parameterize the SGS stress terms in Eqs. (A2) and (A3), a standard Smagorinsky model is used to represent the influence of the eddies smaller than the grid size into the resolved flow structures. The SGS stress terms are $\tau_{i j}=$ $\overline{u_{i} u_{j}}-\bar{u}_{i} \bar{u}_{j}$ for momentum and $q_{i j}=\overline{u_{i} q_{j}}-\bar{u}_{i} \bar{q}_{j}$ for potential temperature. The effect of subgrid-scale motion on the resolved large scales $\tau_{i j}$ is represented by

$\tau_{i j}=-2 v_{\mathrm{t}} \bar{S}_{i j}$,

where $\bar{S}_{i j}=\frac{1}{2}\left(\frac{\partial \bar{u}_{i}}{\partial x_{j}}+\frac{\partial \bar{u}_{j}}{\partial x_{i}}\right)$ is the strain rate tensor and $v_{\mathrm{t}}$ the turbulent eddy viscosity. By taking stratification effects into account, the eddy viscosity is determined by

$$
v_{\mathrm{t}}=\left(C_{\mathrm{s}} \bar{\Delta}\right)^{2} \max \left[0,\left(|\overline{\mathbf{S}}|^{2}\left(1-\frac{R i}{P r}\right)\right)\right]^{1 / 2},
$$

where $R i$ is the Richardson number and $\operatorname{Pr}$ is the turbulent Prandtl number (Lilly, 1962; Smagorinsky, 1963). The Richardson number is defined as

$R i=\frac{\frac{g}{\theta_{\rho}} \frac{\partial \theta_{\rho}}{\partial z}}{|\overline{\mathbf{S}}|^{2}}$,

where $\bar{\Delta}$ is a length scale based on the grid spacing and $C_{\mathrm{s}}=0.2$ is the Smagorinsky coefficient as estimated by Lilly (1967), and using the Einstein summation notation for standardization:

$|\overline{\mathbf{S}}|=\sqrt{2 \bar{S}_{i j} \bar{S}_{i j}}$

By using the cut cell approach, tiny and/or anisotropic cells might occur in the vicinity of topographical structures. Thus, the length scale has to be a function of all local grid spacings in orthogonal direction and prescribed correction functions (cf. Scotti et al., 1993; Jähn et al., 2015).

The cloud microphysics parameterization is based on the two-moment scheme Seifert and Beheng (2006) with adjustments applied from Horn (2012) and without ice phase. In this scheme, mass and number density of the hydrometeor classes' cloud droplets and raindrops are represented. A total of seven microphysical processes are included: condensation/evaporation, $\mathrm{CCN}$ activation to cloud droplets at supersaturated conditions, autoconversion, self-collection of cloud droplets and raindrops, accretion and evaporation of rain. The aerosol activation process is prescribed by a power law function based on grid space supersaturation $s$ :

$N_{\mathrm{CCN}}(S)=N_{\mathrm{CCN}, 1 \%} s^{\kappa}$,

with the hygroscopicity parameter $\kappa=0.462$. By having $\mathrm{CCN}$ number concentration measurements available for different supersaturations, an extrapolated value of the $\mathrm{CCN}$ number concentration at $1 \%$ supersaturation can be determined. It is assumed that all $\mathrm{CCN}$ are activated at a critical supersaturation value of $s_{\max }=1.1 \%$. 
Acknowledgements. The first author was internally funded by TROPOS. The authors thank Bernd Heinold and the two reviewers for their constructive comments. Satellite data were downloaded from NOAA's web archive (ftp://ftp.nnvl.noaa.gov/GOES/). The basemap was provided by the Earth Observatory Team NASA (http://earthobservatory.nasa.gov). High-resolution topography data were provided by the CGIAR-CSI SRTM data set (http://srtm.csi.cgiar.org). Numerical simulations were performed at the HPC cluster of and at the Jülich Supercomputing Centre (JSC). We would also like to thank Thomas Bjerring Kristensen from TROPOS for provision of $\mathrm{CCN}$ data. The SALTRACE campaign was mainly funded by the Helmholtz Association, DLR, LMU and TROPOS.

Edited by: J. Schwarz

\section{References}

Bryan, G. H., Wyngaard, J. C., and Fritsch, J. M.: Resolution requirements for the simulation of deep moist convection, Mon. Weather Rev., 131, 2394-2416, doi:10.1175/15200493(2003)131<2394:RRFTSO>2.0.CO;2, 2003.

Chouza, F., Reitebuch, O., Groß, S., Rahm, S., Freudenthaler, V., Toledano, C., and Weinzierl, B.: Retrieval of aerosol backscatter and extinction from airborne coherent Doppler wind lidar measurements, Atmos. Meas. Tech., 8, 2909-2926, doi:10.5194/amt8-2909-2015, 2015.

DeSouza, R. L.: A study of atmospheric flow over a tropical island, PhD Thesis, Dep. of Meteorol., Florida State University, Tallahassee, 1972.

Doms, G., Förstner, J., Heise, E., Herzog, H.-J., Mironov, D., Raschendorfer, M., Reinhardt, T., Ritter, B., Schrodin, R., Schulz, J.-P., and Vogel, G.: A Description of the Nonhydrostatic Regional COSMO Model, Deutscher Wetterdienst, 2011.

Ellis, W. G. and Merrill, J. T.: Trajectories for Saharan dust transported to Barbados using Stoke's Law to describe gravitational settling, J. Appl. Meteorol., 34, 1716-1726, 1995.

Emanuel, K. A.: Atmospheric Convection, Oxford University Press, 1994.

Engelmann, R., Ansmann, A., Horn, S., Seifert, P., Althausen, D., Tesche, M., Esselborn, M., Fruntke, J., Lieke, K., Freudenthaler, V., and Gross, S.: Doppler lidar studies of heat island effects on vertical mixing of aerosols during SAMUM-2, Tellus, 63B, 448458, 2011.

Esteban, M. A. and Chen, Y.-L.: The impact of trade wind strength on precipitation over the windward side of the island of Hawaii, Mon. Weather Rev., 136, 913-928, 2008.

Etling, D. and Brown, R.: Roll vortices in the planetary boundary layer: a review, Bound.-Lay. Meteorol., 65, 215-248, doi:10.1007/BF00705527, 1993.

$\mathrm{Fu}$, Q. and Liou, K. N.: Parameterization of the radiative properties of cirrus clouds, J. Atmos. Sci., 50, 2008-2025, doi:10.1175/1520-0469(1993)050<2008:POTRPO>2.0.CO;2, 1993.

Garstang, M., Tyson, P. D., and Emmitt, G. D.: The structure of heat islands, Rev. Geophys. Space Ge., 13, 139-165, 1975.

Ge, C., Wang, J., and Reid, J. S.: Mesoscale modeling of smoke transport over the Southeast Asian Maritime Continent: coupling of smoke direct radiative effect below and above the low-level clouds, Atmos. Chem. Phys., 14, 159-174, doi:10.5194/acp-14159-2014, 2014.

Groß, S., Freudenthaler, V., Schepanski, K., Toledano, C., Schäfler, A., Ansmann, A., and Weinzierl, B.: Optical properties of longrange transported Saharan dust over Barbados as measured by dual-wavelength depolarization Raman lidar measurements, Atmos. Chem. Phys., 15, 11067-11080, doi:10.5194/acp-1511067-2015, 2015.

Horn, S.: ASAMgpu V1.0 - a moist fully compressible atmospheric model using graphics processing units (GPUs), Geosci. Model Dev., 5, 345-353, doi:10.5194/gmd-5-345-2012, 2012.

Jähn, M., Knoth, O., König, M., and Vogelsberg, U.: ASAM v2.7: a compressible atmospheric model with a Cartesian cut cell approach, Geosci. Model Dev., 8, 317-340, doi:10.5194/gmd-8317-2015, 2015.

Kirshbaum, D. J. and Fairman, J. G.: Cloud trails past the Lesser Antilles, Mon. Weather Rev., 143, 995-1017, doi:10.1175/MWR-D-14-00254.1, 2015.

Kirshbaum, D. J. and Grant, A. L. M.: Invigoration of cumulus cloud fields by mesoscale ascent, Q. J. Roy. Meteor. Soc., 138, 2136-2150, doi:10.1002/qj.1954, 2012.

Kirshbaum, D. J. and Wang, C.-C.: Boundary layer updrafts driven by airflow over heated terrain, J. Atmos. Sci., 71, 1425-1442, doi:10.1175/JAS-D-13-0287.1, 2014.

Lilly, D. K.: On the numerical simulation of buoyant convection, Tellus, 14, 148-172, doi:10.1111/j.2153-3490.1962.tb00128.x, 1962.

Lilly, D. K.: The representation of small scale turbulence in numerical simulation experiments, IBM Scientific Computing Symposium on Environmental Sciences, 195-210, 1967.

Mahrer, Y. and Pielke, R. A.: Numierical simulation of the airflow over Barbados, Mon. Weather Rev., 104, 1392-1402, 1976.

Minda, H., Furuzawa, F. A., Satoh, S., and Nakamura, K.: Convective boundary layer above a subtropical island observed by $\mathrm{C}$-band radar and interpretation using a cloud resolving model, J. Meteorol. Soc. Jpn., 88, 285-312, 2010.

Minder, J. R., Smith, R. B., and Nugent, A. D.: The dynamics of ascent-forced orographic convection in the tropics: results from Dominica, J. Atmos. Sci., 70, 4067-4088, 2013.

Monin, A. S. and Obukhov, A. M.: Basic turbulence mixing laws in the atmospheric surface layer, Tr. Inst. Teor. Geofiz. Akad. SSSR, 24, 163-187, 1954.

Muñoz-Esparza, D., Kosović, B., Mirocha, J., and van Beeck, J.: Bridging the transition from mesoscale to microscale turbulence in numerical weather prediction models, Bound.-Lay. Meteorol., 153, 409-440, doi:10.1007/s10546-014-9956-9, 2014.

Muñoz-Esparza, D., Kosović, B., van Beeck, J., and Mirocha, J.: A stochastic perturbation method to generate inflow turbulence in large-eddy simulation models: application to neutrally stratified atmospheric boundary layers, Phys. Fluids, 27, 035102, doi:10.1063/1.4913572, 2015.

Prospero, J. and Carlson, T.: Radon-222 in the North Atlantic trade winds: Its relationship to dust transport from Africa, Science, 167, 974-977, 1970.

Prospero, J., Bonatti, E., Schubert, C., and Carlson, T.: Dust in the Caribbean atmosphere traced to an African dust storm, Earth Plan. Sci. Lett., 9, 287-293, 1970. 
Reitebuch, O.: Wind lidar for atmospheric research, in: Atmospheric Physics - Background, Methods, Trends, Springer Series on Research Topics in Aerospace, Springer, Berlin/Heidelberg, 487-507, 2012.

Savijärvi, H. and Matthews, S.: Flow over Small Heat Islands: a numerical sensitivity study, J. Atmos. Sci., 61, 859-868, 2004.

Scotti, A., Meneveau, C., and Lilly, D. K.: Generalized Smagorinsky model for anisotropic grids, Phys. Fluids A, 5, 2306-2308, 1993.

Seifert, A. and Beheng, K. D.: A two-moment cloud microphysics parameterization for mixed-phase clouds, Meteorol. Atmos. Phys., 92, 45-66, 2006.

Siebert, H., Beals, M., Bethke, J., Bierwirth, E., Conrath, T., Dieckmann, K., Ditas, F., Ehrlich, A., Farrell, D., Hartmann, S., Izaguirre, M. A., Katzwinkel, J., Nuijens, L., Roberts, G., Schäfer, M., Shaw, R. A., Schmeissner, T., Serikov, I., Stevens, B., Stratmann, F., Wehner, B., Wendisch, M., Werner, F., and Wex, H.: The fine-scale structure of the trade wind cumuli over Barbados - an introduction to the CARRIBA project, Atmos. Chem. Phys., 13, 10061-10077, doi:10.5194/acp-13-10061-2013, 2013.
Siebesma, A. P., Bretherton, C. S., Brown, A., Chlond, A., Cuxart, J., Duynkerke, P. G., Jiang, H., Khairoutdinov, M., Lewellen, D., Moeng, C.-H., Sanchez, E., Stevens, B., and Stevens, D. E.: A large eddy simulation intercomparison study of shallow cumulus convection, J. Atmos. Sci., 60, 1201-1219, doi:10.1175/15200469(2003)60<1201:ALESIS>2.0.CO;2, 2003.

Smagorinsky, J.: General circulation experiments with the primitive equations, Mon. Weather Rev., 164, 91-99, 1963.

Smith, R. B., Gleason, A. C., and Gluhosky, P. A.: The Wake of St. Vincent, J. Atmos. Sci., 54, 606-623, 1997.

Smith, R. B., Schafer, P., Kirshbaum, D. J., and Regina, E.: Orographic precipitation in the tropics: experiments in Dominica, J. Atmos. Sci., 66, 1698-1716, 2009.

Tesche, M., Groß, S., Ansmann, A., Müller, D., Althausen, D., Freudenthaler, V and Esselborn, M: Profiling of Saharan dust and biomass burning smoke with multiwavelength polarization Raman lidar at Cape Verde, Tellus, 63B, 649-676, 2011.

Wyngaard, J. C.: Toward numerical modeling in the "Terra Incognita", J. Atmos. Sci., 61, 1816-1826, doi:10.1175/15200469(2004)061<1816:TNMITT>2.0.CO;2, 2004. 